\title{
BIOCLIMATIC CLASSIFICATION OF CENTRAL IRAN USING MULTIVARIATE STATISTICAL METHODS
}

\author{
KhATIBI, R. ${ }^{1 *}-$ SOLTANI, S. $^{2}-$ KHODAGHOLI, M. $^{3}$ \\ ${ }^{I}$ Natural Resource Faculty of Isfahan University of Technology, Isfahan, Iran \\ (tel: +989019438092$)$ \\ ${ }^{2}$ Department of Natural Resources, Isfahan University of Technology, Isfahan, 84156-83111, \\ Iran (e-mail: ssoltani@cc.iut.ac.ir; tel: +989133104434; fax: +98983113912840) \\ ${ }^{3}$ Soil Conservation and Watershed Management Research Department, Isfahan Agricultural \\ and Natural Resources Research and Education Center, AREEO, Isfahan, Iran \\ (e-mail:m_khodagholi@yahoo.com; tel: +989133265318) \\ *Corresponding author \\ e-mail:r_khatibi60@yahoo.com \\ (Received 24 $4^{\text {th }}$ May 2016; accepted $13^{\text {th }}$ Jul 2016)
}

\begin{abstract}
Effective management and proper exploitation of each ecosystem requires a comprehensive understanding of its components. Climate can exert direct and indirect effects on all components of ecosystems. While most systems of bioclimatic classification depend on limited variables such as precipitation, temperature, and their combinations, describing the climate of a region requires the evaluation of more factors. The present study was an attempt toward the bioclimatic classification of central areas of Iran (including Isfahan, Yazd, and Kerman Provinces). Using multivariate statistical methods, 156 climatic variables, which affected the distribution of dominant plant species in the study area, were selected. After performing principal component analysis to identify the main factors, cluster analysis was conducted to determine the bioclimatic classes and their characteristics. Overall, seven climatic factors (i.e. temperature, warm season precipitation and relative humidity, spring and cold season precipitation, wind speed, cloudy and partly cloudy days, Radiation, and dust) were found to explain $91.01 \%$ of the total variance in primary variables. Cluster analysis Ward's method divided the study area into 13 bioclimatic zones. The comparison of the obtained results with the results of four common methods of climate classification (Köppen's, Gaussen's, Emberger's, and de Martonne's methods) suggested the higher ability of multivariate statistical methods to discriminate between bioclimatic zones. The dominant species in each zone were finally described.
\end{abstract}

Keywords: factor analysis, bioclimatic classification, central Iran, multivariate statistical methods, common methods, climatic variables

\section{Introduction}

Climatic zoning involves the identification of zones and regions with similar climate. Numerous researchers including Köppen, Emberger, de Martonne, Ivanov, Hansen, and Silianinov have focused on developing methods of climate classification. Climate is the most important determinant of vegetation cover at the global scale. Despite their significance, other factors such as soil, topography, and human are less important than climate in determining plant species in an area (Retueto and Carballeira, 1992). Due to different weather conditions, a variety of climates and vegetation areas have developed on Earth. Climate also affects the biological properties and distribution of plants and creates distinguishable vegetation types in various parts of the world (Sabeti, 1962). Since plants can well reflect the effects of environmental and natural phenomena, they play a major role in climate classification (Jafarpour, 2000). Following the development 
of accurate quantitative methods, conventional climate classification approaches have been preceded by novel methods such as factor analysis and cluster analysis. Such novel techniques distinguish climate zones based on statistical climate data rather than the researcher's opinion (Masoudian, 2003). Sabeti (1969) and Javanshir (1975) were the first researchers who used multivariate techniques for climate classification in Iran. Masoudian (2003) evaluated 37 climatic factors at an annual level and concluded that Iran's climate consisted of six climate factors and 15 climate regions. Pabout (1969) divided Iran to three bioclimatic zones, namely Caspian, Irano-Turanian, and Baluchi climates. This classification was performed mainly based on rainfall (although elevation was also taken into account in case of the Caspian climate). Despite its shortcomings, Pabout's classification was a valuable system considering the lack of climatic information at that time. Javier Amigo et al. (1988) extracted rainfall and temperature data from 140 weather stations in Chile and classified the country into four bioclimatic zones, i.e. tropical, Mediterranean, temperate, and northern climates. Ndetto et al. (2013) performed a basis analysis of climate and urban bioclimate of Dar es Salaam city in Tanzania. They argued that in a world affected by urbanization and climate changes, it is necessary to clarify the urban microclimate and bioclimate in different areas. They hence used synoptic meteorological data (from 2001 to 2011) to assess urban climate and human biometeorological conditions. In an attempt toward the phytosociological and bioclimatic classification of Pacific coasts in North America, Peinado et al. (1997) adopted Blanquet's approach and cluster analysis and identified 22 vegetation regions and floristic associations which were characterized by their floristic composition. Immediately after the end of World War II, Belasco (1988) created a vegetation map of Toulouse (France) and identified three vegetation zones, including Toulouse, Montpellier, and Granoble, in the area. According to Pedrotti (2012), numerous types of vegetation maps can exist since different intrinsic properties (e.g. floristic compositions), structures, and population dynamics of floristic associations can each yield a specific map. Moreover, maps may be different due to their scales and mixed characteristics. In a study on the application of climatic parameters in vegetation distribution, Gavilan (2005) used over 100 phytoclimatic indices and climatic parameters extracted from 260 weather stations in Iberian Peninsula (Spain). The results of multivariate and estimative statistical methods showed different levels of correlation between climatic parameters. After categorizing 111 climatic parameters into five larger groups, temperature and precipitation were found to have the greatest effects on vegetation distribution. DeGaetano and Schulman (1990) classified agricultural climates of USA and Canada using the principal component analysis and cluster analysis. Primary variables in this classification included maximum temperature, minimum temperature, relative humidity, wind speed, number of shiny hours and precipitation. This classification has similarities with boundary of natural perennial species in accordance with the use of many variables. In a study in Minas Gerias (Brazil), de Sá Júnior et al. (2011) applied Köppen's method for climate classification using raster precipitation and temperature data during 1961-1990. They presented a map of the obtained climate classes, i.e. tropical rainy climate, dry climate, and temperate tropical climate. Yurdanur et al. (2003) specified climatic regions of Turkey using cluster analysis. In this study, five different techniques were applied initially to decide the most suitable method for the region. They concluded that Ward's method was the most likely one to yield acceptable results. In this study, seven different climatic zones were found. Dinpajouh et al. (2003) used multivariate statistical methods for climate classification of 
Iran in their agricultural studies. Using factor analysis, Saligheh et al. (2008) and Gerami Motlagh et al. (2006) reported Sistan and Baluchestan and Boushehr Provinces (Iran) to have respectively five and six climate zones. In an attempt toward bioclimatic classification of Chaharmahal and Bakhtiari Province (Iran), Soltani et al. (2011) adopted multivariate statistical methods and factor analysis using 71 climatic factors with greatest effects on distribution of vegetation. The most important factors in factor analysis were temperature, precipitation, and Radiation which explained $91.8 \%$ of variance in primary variables. Hierarchical cluster analysis based on Ward's method lead to the identification of five bioclimatic zones in the province. Yaghmayi et al. (2009) used multivariate statistical methods for the bioclimatic classification of Isfahan Province (Iran). They found precipitation, wind, and Radiation to explain $92.3 \%$ of variance in primary variables. Cluster analysis of these three factors revealed seven bioclimatic zones in the province. It is critical to apply a comprehensive method which uses most effective climatic factors to provide a realistic image of an area's climate. Statistical methods mainly aim to maximize intragroup homogeneity and intergroup heterogeneity, i.e. climatic zones need to have the greatest level of internal homogeneity while maintaining maximum difference with each other (Kaviani, 1999). The present study used multivariate statistical methods for the bioclimatic classification of central Iran (including Kerman, Isfahan, and Yazd Provinces). The results were then compared with the traditional (common) classifications based on Köppen, Gaussen, Emberger, and de Martonne methods.

\section{Materials and Methods}

\section{Study area}

As Figure 1 shows, the study area was located in central Iran and covered three provinces (Isfahan, Yazd, and Kerman).

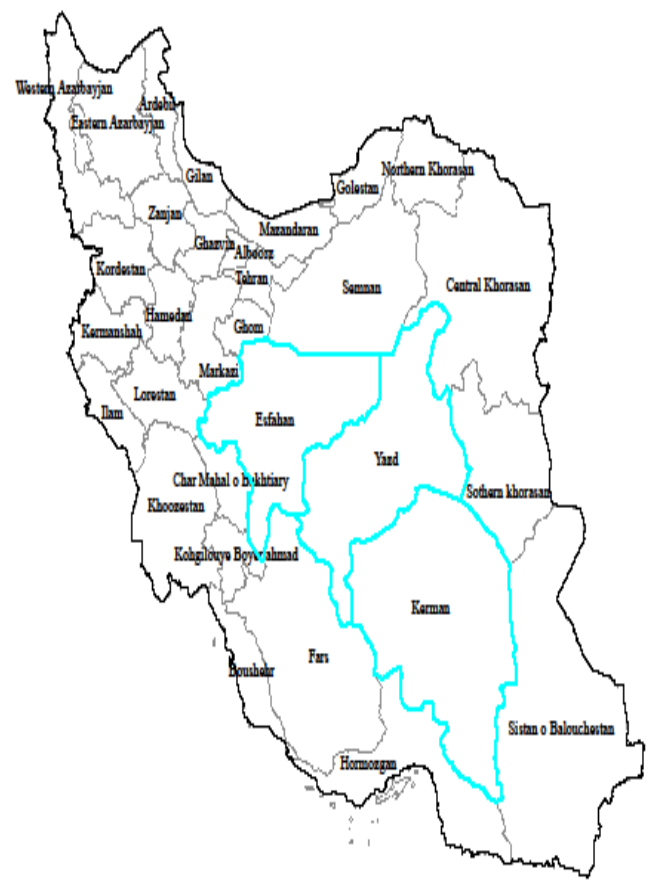

Figure 1. The study area (includes: 3 provinces of Kerman, Yazd and Isfahan 


\section{Methods}

In the present study, 156 climatic variables with the greatest effects on the distribution of dominant plant species and vegetation types in the study area were extracted from the data provided by Iran Meteorological Organization (Table 1). Data were obtained from synoptic and climatology stations in the mentioned provinces and their adjacent areas. The collected data were checked for accuracy and then used to create a database. Evaluations were made over a 20-year period from 1990 to 2010. The geographical location of the studied points is presented in Figure 2.

Table 1.Climatic and bioclimatic variables included within the classification

\begin{tabular}{|l|c|c|}
\hline \multicolumn{1}{|c|}{ Variable type(Monthly and annual) } & Unit & $\begin{array}{c}\text { Number } \\
\text { of } \\
\text { Variables }\end{array}$ \\
\hline The average of minimum temperature & ${ }^{\circ}$ C & 7 \\
\hline Freezing days & daily & 4 \\
\hline The average of maximum temperature & ${ }^{\circ}$ C & 9 \\
\hline The average of temperature & ${ }^{\circ}$ C & 13 \\
\hline The average of Relative humidity & percent & 7 \\
\hline The average of maximum Relative humidity & percent & 7 \\
\hline The average of minimum Relative humidity & percent & 6 \\
\hline Monthly Precipitation & mm & 12 \\
\hline Days with Precipitation greater than or equal to 10 & $\mathrm{mm}$ & 13 \\
\hline Days with Precipitation & $\mathrm{mm}$ & 13 \\
\hline Days with Thunder storm & daily & 6 \\
\hline Days with Dust & daily & 7 \\
\hline The average of Wind speed & $\mathrm{knote}$ & 13 \\
\hline Days with partly cloudy & daily & 8 \\
\hline Days with cloudy & daily & 6 \\
\hline Sunshine & hours & 9 \\
\hline Winter Precipitation & $\mathrm{mm}$ & 1 \\
\hline Spring Precipitation & $\mathrm{mm}$ & 1 \\
\hline Summer Precipitation & $\mathrm{mm}$ & 1 \\
\hline Autumn Precipitation & $\mathrm{mm}$ & 1 \\
\hline Days with Precipitation greater than or equal to 10 of winter season & $\mathrm{mm}$ & 1 \\
\hline Days with Precipitation greater than or equal to 10 of spring season & $\mathrm{mm}$ & 1 \\
\hline Days with Precipitation greater than or equal to 10 of summer season & $\mathrm{mm}$ & 1 \\
\hline Days with Precipitation greater than or equal to 10 of fall season & $\mathrm{mm}$ & 1 \\
\hline Days with Precipitation of winter season & $\mathrm{mm}$ & 1 \\
\hline Days with Precipitation of spring season & $\mathrm{mm}$ & 1 \\
\hline Days with Precipitation of summer season & $\mathrm{mm}$ & 1 \\
\hline Days with Precipitation of fall season & $\mathrm{mm}$ & 1 \\
\hline Days with Precipitation greater than or equal to 5 of winter season & $\mathrm{mm}$ & 1 \\
\hline Days with Precipitation greater than or equal to 5 of spring season & $\mathrm{mm}$ & 1 \\
\hline Days with Precipitation greater than or equal to 5 of summer season & $\mathrm{mm}$ & 1 \\
\hline Days with Precipitation greater than or equal to 5 of fall season & $\mathrm{mm}$ & 1 \\
\hline & & \\
\hline
\end{tabular}




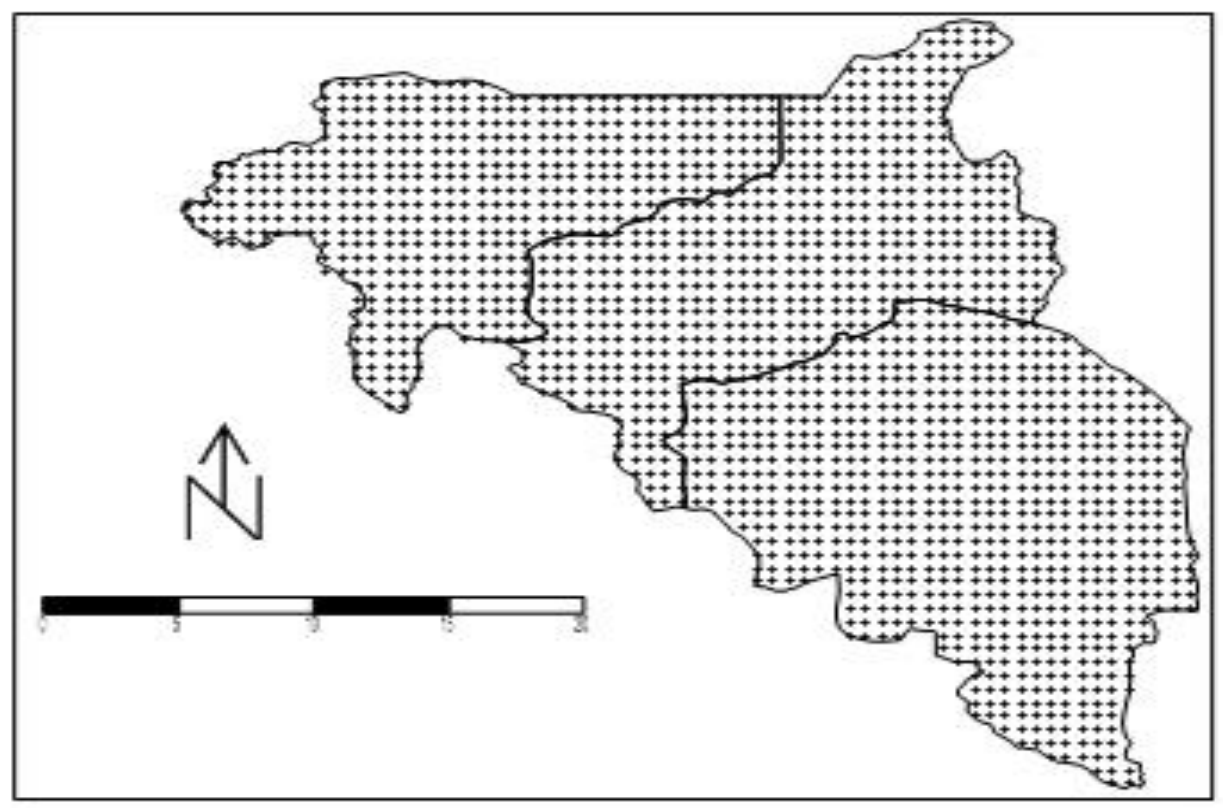

Figure 2. Geographical location of investigation points under study area

The results of climate analysis cannot be generalized to broad zones unless interpolation techniques are adopted to convert discrete data to continuous data (Khodagholi, 2006). Considering the density and variability of the selected variables in the current study, a variogram analysis using the most variable parameter, i.e. precipitation, was performed to determine the appropriate grid size. Ultimately, a $15 \mathrm{~km}$ $\times 15 \mathrm{~km}$ grid was used for the interpolation of climatic parameters in the study area. The result was a matrix with 156 columns (variables) and 1762 rows (locations). Kriging was then conducted to estimate all the 156 variables at all 1762 points (pixels). A factor analysis, with the obtained values as inputs, was performed to evaluate the climatic conditions of central Iran.

Factor analysis serves as a data reduction tool. Predictions made by this tool about the unobservable factors will be used in subsequent analysis. The ultimate goal of factor analysis is to produce matrices of factor loadings and factor scores, which are used as the basis for all interpretations. Factor loadings are correlations between input variables and factors obtained from the analysis. Factor scores describe the spatial patterns of the factors throughout the study area. They are used not only in creating factor maps, but also as preliminary data in cluster analysis. Principal component analysis and varimax rotation were applied on the preliminary data matrix to reduce the number of variables. Since factors with eigenvalues below one are not superior to a main variable (which has a variance of one) (Seyedan et al., 1997), factors with eigenvalues more than one were selected.Also,based on results, the Scree Plot introduced seven factors were suitable for this research (Figure 3). Kaiser-Meyer-Olkin (KMO) measure was then used to determine the effectiveness of factor analysis (Table 2). The calculated KMO index (0.98) showed the perfect performance of the factor analysis.

Since bioclimatic classification of the study area was the main goal of this research, hierarchical cluster analysis based on Ward's method was applied on the factor scores matrix. Hierarchical cluster analysis applies a set of algorithms and techniques to build clusters based on the existing similarities and dissimilarities (Everitt et al., 2005). 
Ward's method actually minimizes the variance within clusters, while maximizing the variance between clusters (Farshadfar, 2001). After clustering the matrix of factor scores using the mentioned method, the scores of cells within each cluster were summed and the most significant factor in each area. Finally, the climate of central Iran (including Isfahan, Yazd, and Kerman Provinces) was classified and each class was named based on the sum of factor scores and primary climatic variables. Afterward, kriging was performed on the vegetation map of the study and vegetation types were determined at all 1762 locations (cells of the grid). The relations between vegetation types and climatic variables were then evaluated. The factor score of each area can best describe the most important climatic feature of that area since these scores are the outcome of numerous subgroup variables.

\section{Results}

The first step in the administration of factor analysis is to confirm its performance (through methods such as the KMO index). According to Kaiser, who considers KMO index values above 0.9 as indicators of excellent performance of factor analysis (Farshadfar, 2001), the factor analysis had great performance in the present study (KMO index $=0.98$ ). Factor analysis of the matrix of preliminary data yielded seven factors with eigenvalues above one (Table 3). These seven factors explained $91.01 \%$ of the total variance in preliminary data and produced the bioclimatic classes in the study area (Isfahan, Yazd, and Kerman Provinces).

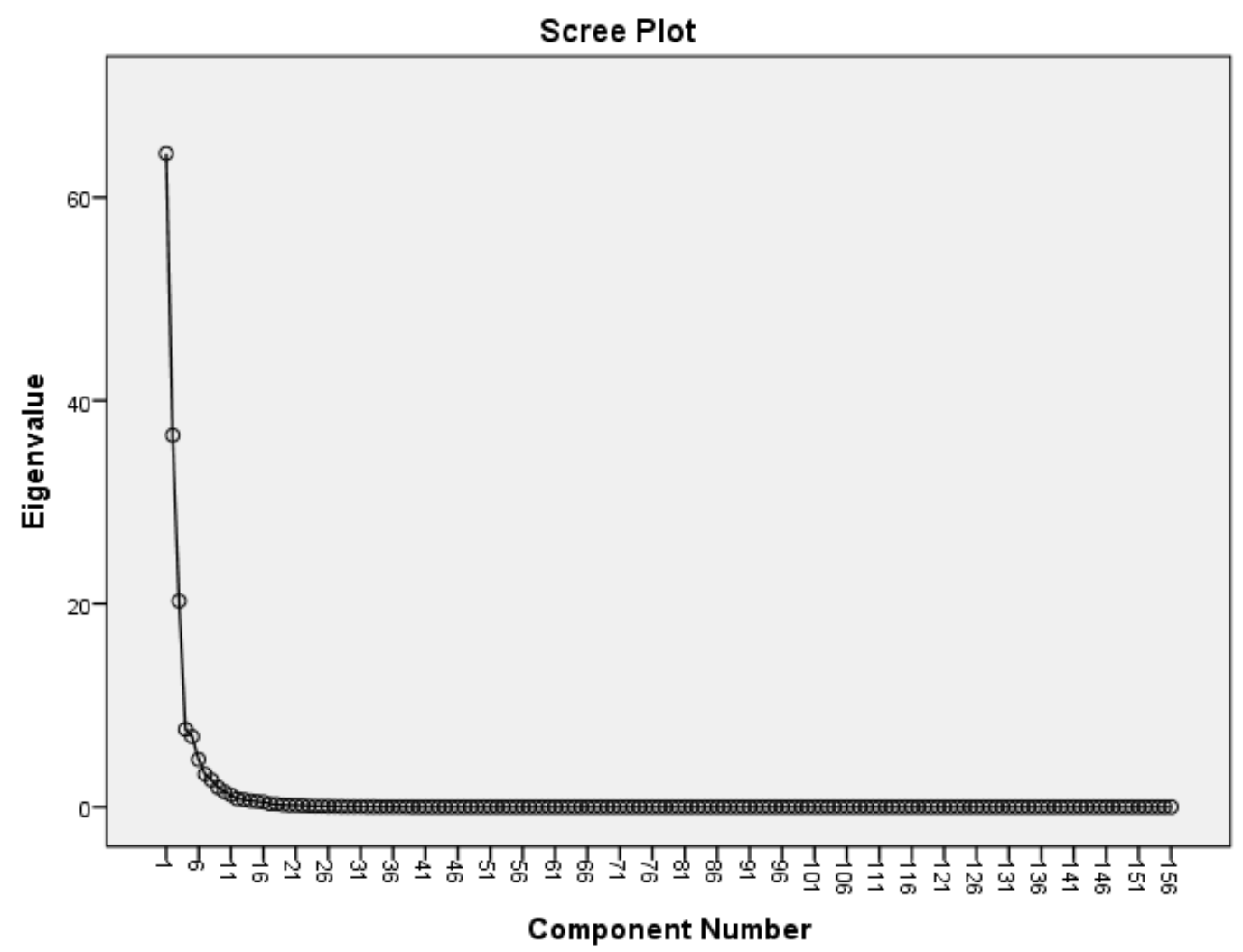

Figure 3. The Scree Plot graph that represents the number of appropriate factors 
Table 2. View about Coefficient K.M.O

\begin{tabular}{|c|c|}
\hline Amount of K.M.O & Data fit for factor analysis \\
\hline Greater than or equal to 90 & perfect \\
\hline $80-90$ percent & Very good \\
\hline $70-80$ percent & good \\
\hline $60-70$ percent & normal \\
\hline $50-60$ percent & weak \\
\hline Less than 50 percent & unacceptable \\
\hline
\end{tabular}

Table 3. The Eigen Value, percent variance and the cumulative variance of each factor

\begin{tabular}{|c|c|c|c|}
\hline factors & Eigen Value & Variance (\%) & Cumulative (\%) \\
\hline 1 & 41.22 & 28.44 & 28.44 \\
\hline 2 & 23.45 & 20.42 & 48.86 \\
\hline 3 & 12.99 & 17.12 & 66.00 \\
\hline 4 & 4.89 & 9.13 & 75.13 \\
\hline 5 & 4.44 & 8.05 & 83.19 \\
\hline 6 & 2.99 & 4.61 & 87.80 \\
\hline 7 & 2.06 & 3.20 & 91.01 \\
\hline
\end{tabular}

The factor loading matrix, showing correlations between variables and factors, was also obtained from factor analysis and varimax rotation. The elements of the matrix were first arranged based on their absolute values. Values over \pm 0.7 were then retained and others were eliminated (Table 4). Since absolute values below 0.7 were equal to or less than 0.3 , a cut-off point of 0.7 was selected. Moreover, values over \pm 0.7 could reflect correlations between parameters and factors. Factor scores are standardized values with a mean value of zero (which shows the factor score in that area) and a variance of one. 
Table 4. Rotated factor loading matrix greater than \pm 0.7

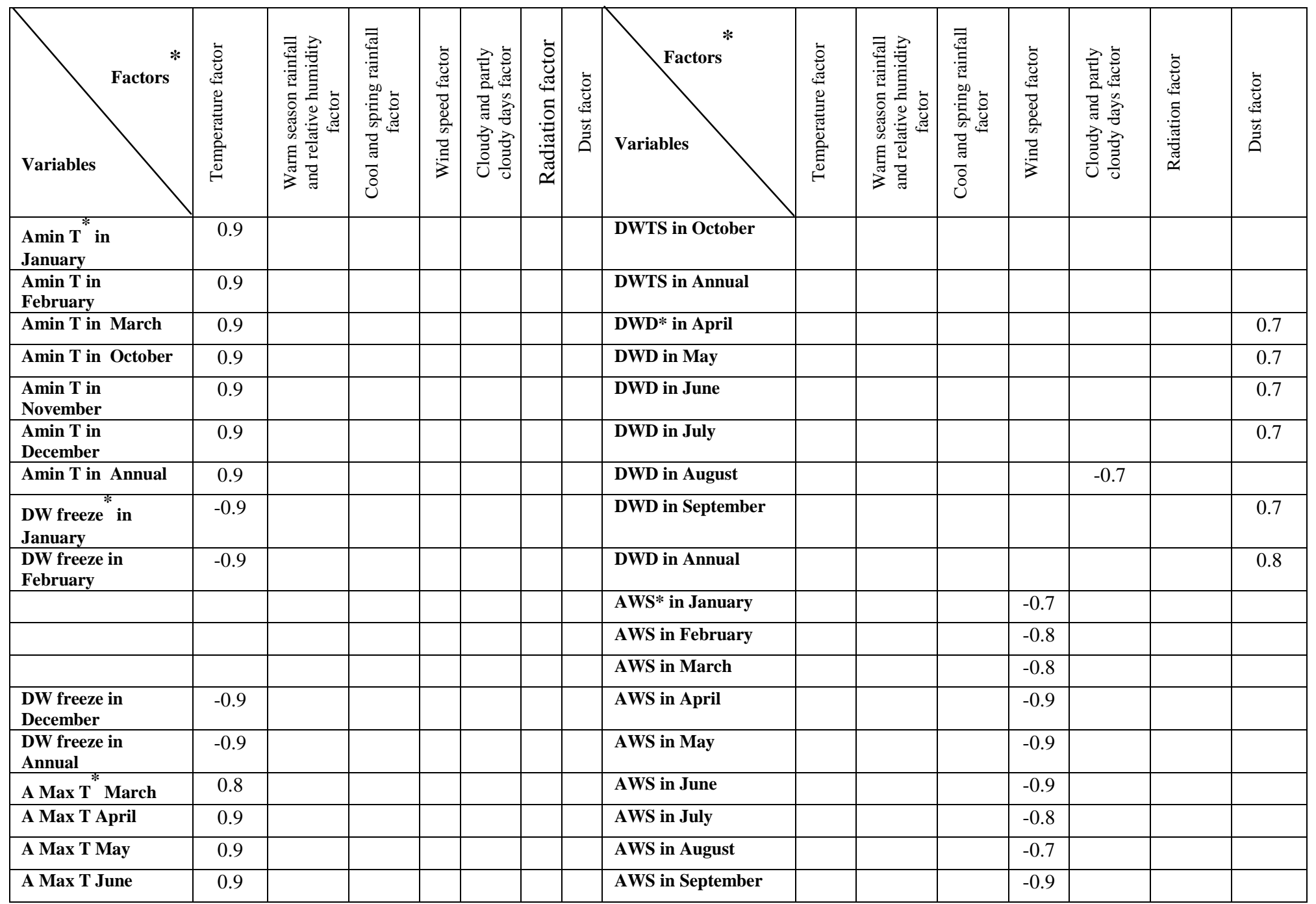

APPLIED ECOLOGY AND ENVIRONMENTAL RESEARCH 14(4): 191-231.

http://www.aloki.hu • ISSN 15891623 (Print) • ISSN 17850037 (Online)

DOI: http://dx.doi.org/10.15666/aeer/1404_191231

(c) 2016, ALÖKI Kft., Budapest, Hungary 


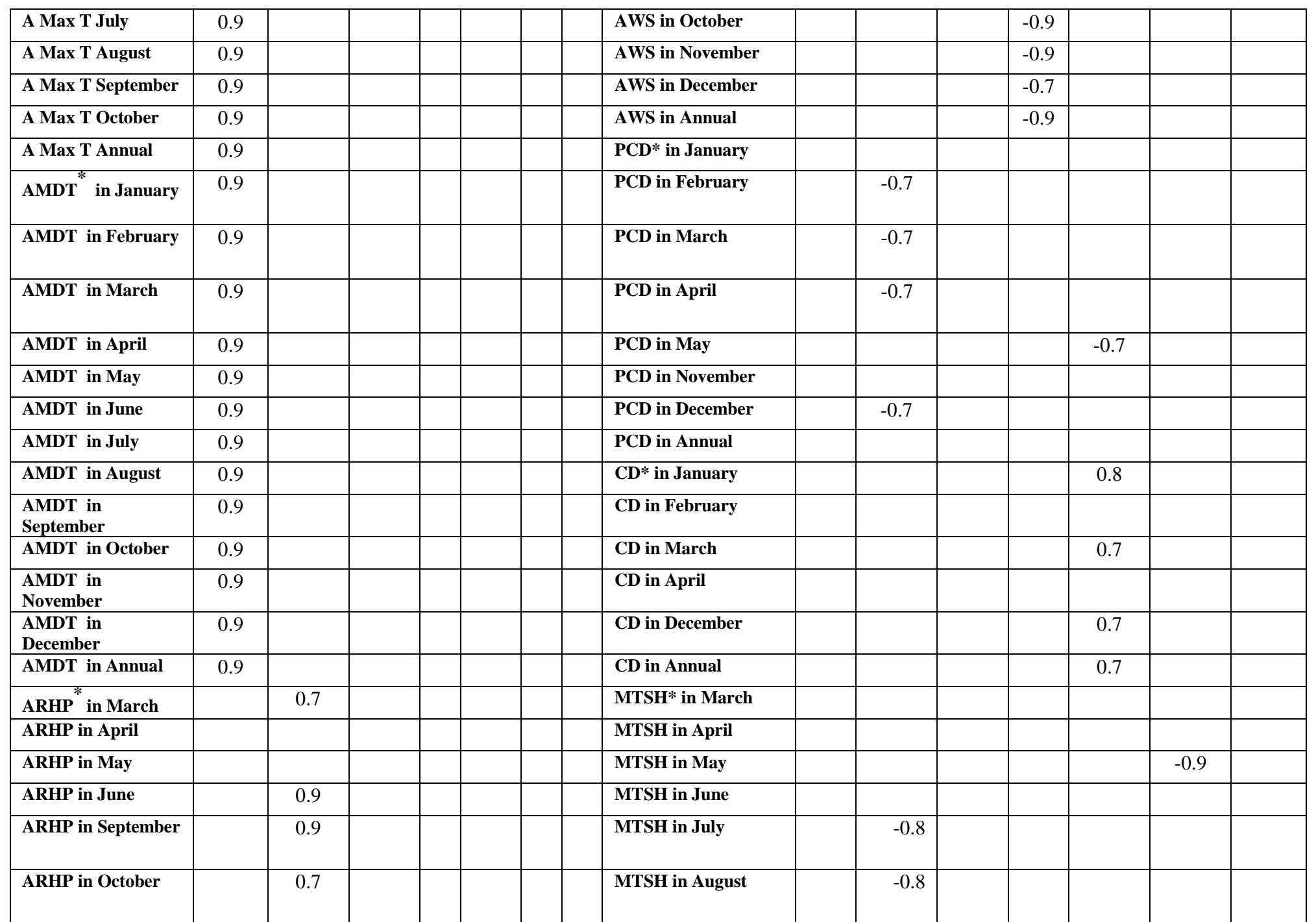




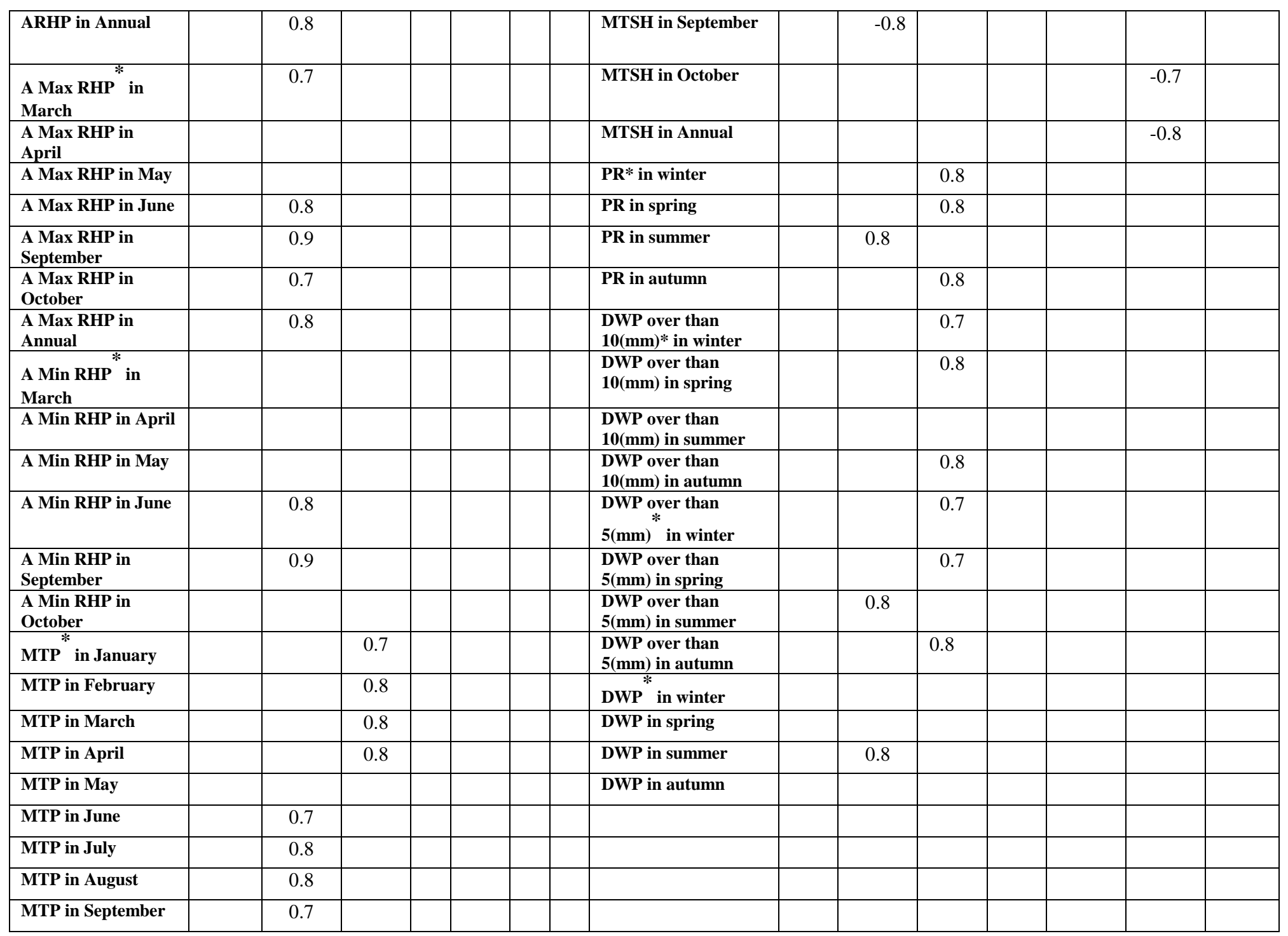




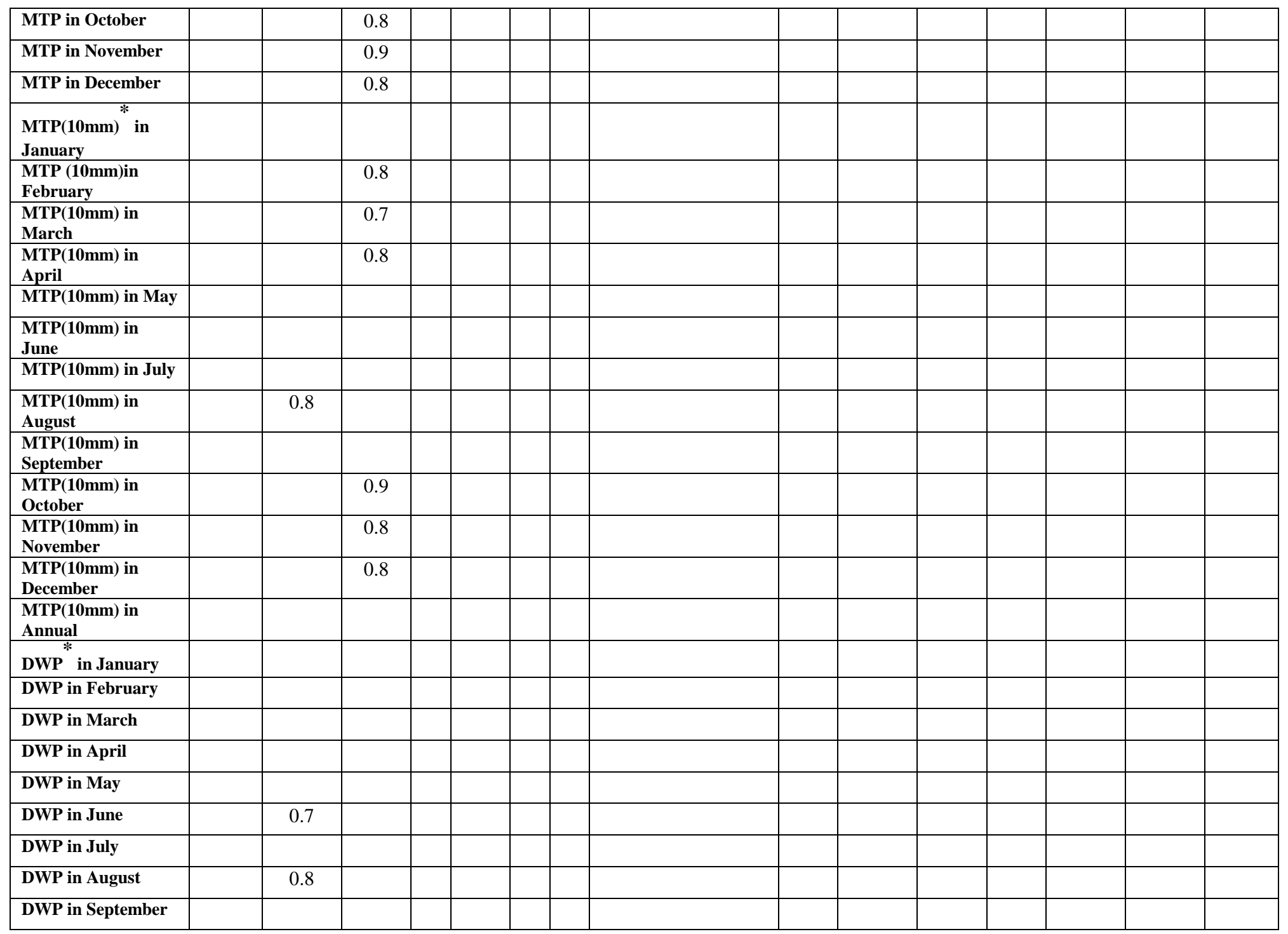




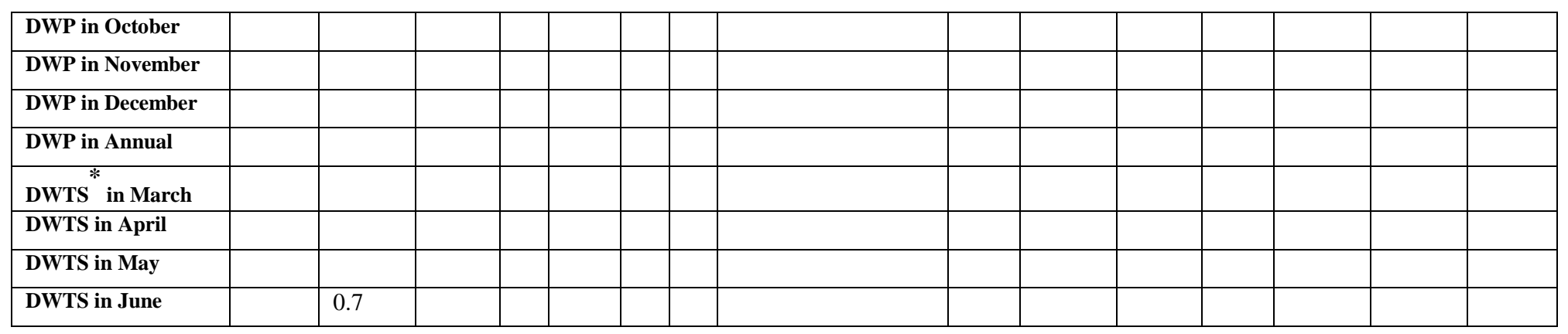

The abbreviations marked with an asterisk (*) in Table 4 are:

Amin T: Average minimum temperature, DW freeze: Day with freezing, A Max T: Average maximum temperature, AMDT: Average mean daily temperature, ARHP: Average relative humidity percent, A Max RHP: Average maximum relative humidity percent, A Min RHP: Average minimum relative humidity percent, MTP: Monthly total precipitation, MTP(10mm): Days with precipitation over $10 \mathrm{~mm}$ in month, DWP: Days with precipitation, DWTS: Days with thunder storm, DWD: Days with dust, AWS: Average wind speed, PCD: Partly cloudy days, CD: Cloudy days, MTSH: Monthly total sunshine, PR: Precipitation . 
Ultimately, the following factors were extracted and named.

\section{Temperature factor}

This factor, which owed its name to the incorporation of all variables related to temperature (i.e. maximum and minimum monthly temperature and daily temperature during the 12 months of the year), explained $28.45 \%$ of the total variance in primary variables. Temperature had positive or negative correlations over 0.7 with 33 variables (Table 4). Figure 4 shows the spatial distribution of this factor in the three studied provinces (central Iran). As seen, western areas in Isfahan and Yazd have lower temperature compared to their eastern parts (because of its proximity to the Zagros Mountains, according to the map of Figure 16). In Kerman, however, eastern areas had cold and negative temperature while eastern areas had hot and positive temperature (because of its proximity to the Dasht-E-Kavir and Dasht-e Lut, according to the map of Figure 16).

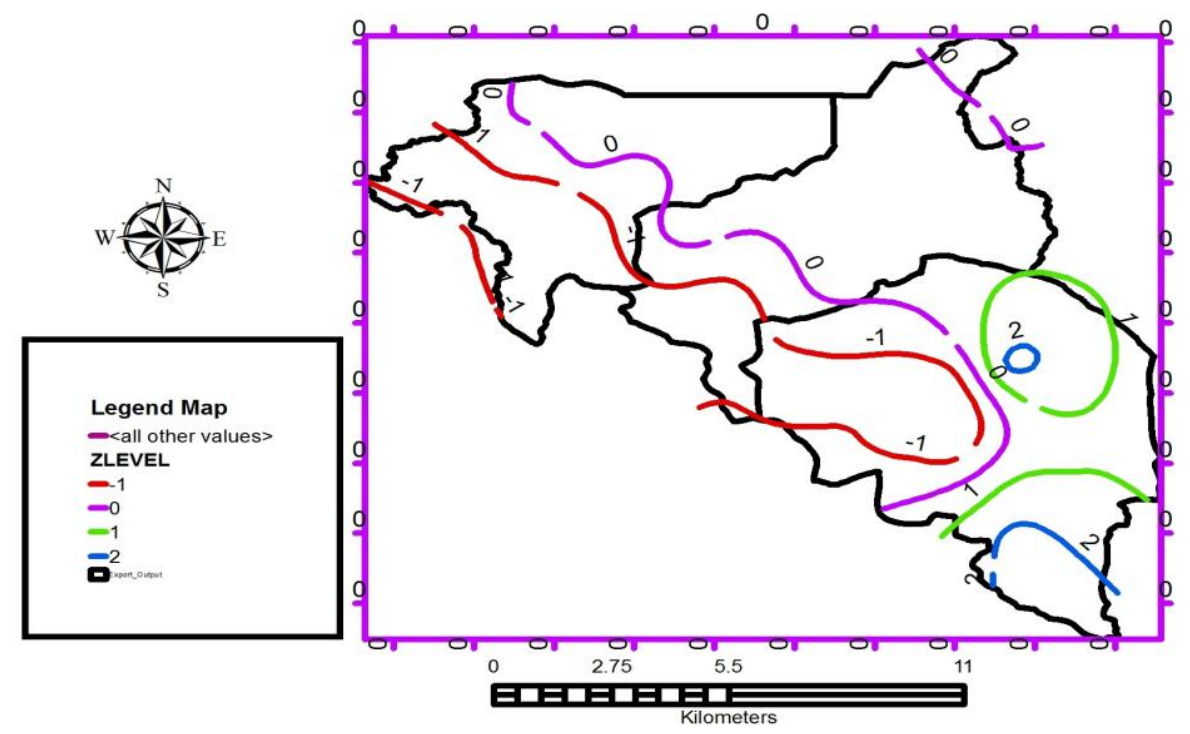

Figure 4. Spatial distribution of temperature factor in the study area

\section{Relative humidity and warm season rainfall factor}

This factor alone explained $20.43 \%$ of variance in primary variables. It had strong correlations (>0.7) with 30 variables including the mean relative humidity in March, June, September, and October, mean maximum relative humidity in the mentioned months, mean annual maximum relative humidity, and precipitation in June, July, August, and September (Table 4). Based on the spatial distribution of this factor (Figure 5 ), its lowest level was observed in the northeastern parts of Kerman Province and eastern parts of Yazd Province. Relative humidity and warm rain was the highest in the southern areas of Kerman Province which are close to the Persian Gulf and Oman Sea (Figure 16). 


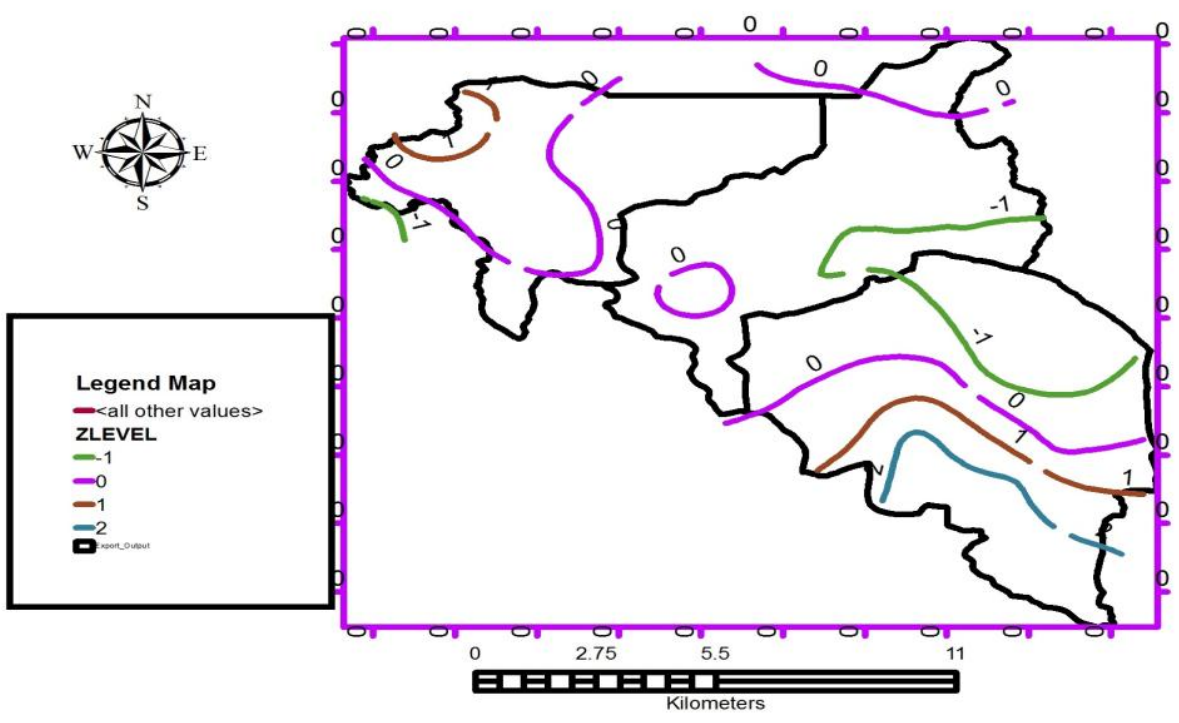

Figure 5. Spatial distribution of relative humidity and warm season rainfall factor in the study area

\section{Spring and cold season rainfall factor}

This factor could explain $17.13 \%$ of the total variance in primary variables and had strong correlations $(> \pm 0.7)$ with 22 variables such as precipitation in January, February, March, April, October, November, and December and days with precipitation over $10 \mathrm{~mm}$ in February, March, and April (Table 4). According to Figure 6, the maximum level of this factor was detected in the western areas of Isfahan Province. This indicates high precipitation in these areas during spring and cold seasons of the year.

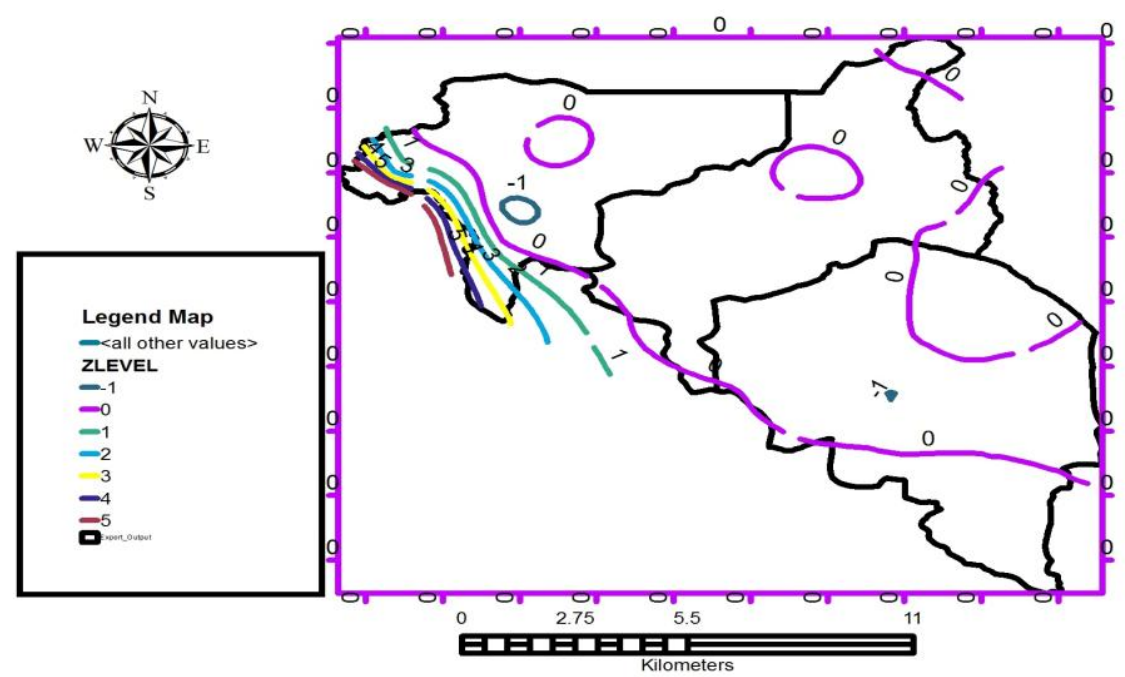

Figure 6. Spatial distribution of cool and spring rainfall season factor in the study area 


\section{Wind speed factor}

All variables related to wind speed (e.g. mean wind speed in January, February, and March) were categorized in a factor called "wind speed". This factor, whose spatial distribution is presented in Figure 7, explained $9.13 \%$ of the total variance in primary variables. Apparently, the distribution of this factor in the three studied provinces ranged between -1 and +3 . Its highest distribution was seen in northern and eastern parts of Isfahan Province, eastern parts of Yazd Province, and southern parts of Kerman Province.

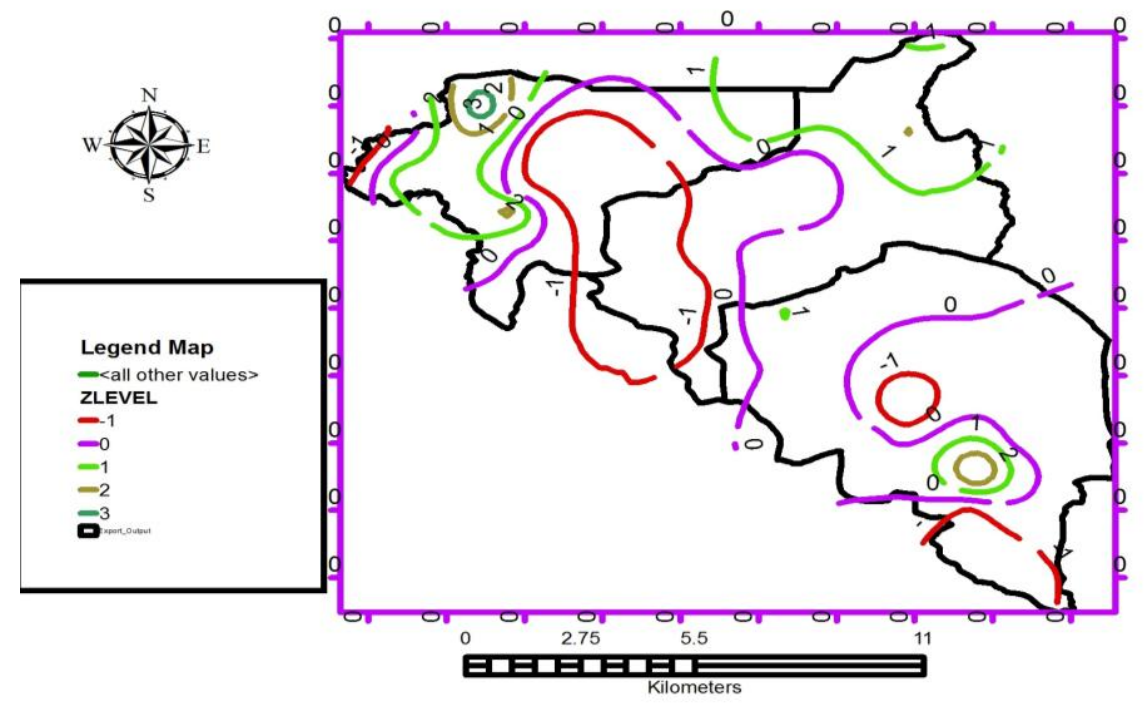

Figure 7. Spatial distribution of wind speed factor in the study area

\section{Cloudy and partly cloudy days factor}

This factor explained $8.03 \%$ of the total variance in primary variables and had strong correlations $(> \pm 0.7)$ with number of partly cloudy days in May, number of cloudy days in January and March-December, and annual number of cloudy days. As its spatial distribution map (Figure 8) shows, this factor had the greatest distribution (ranging between 0 and +3 ) in Isfahan and Yazd Provinces.

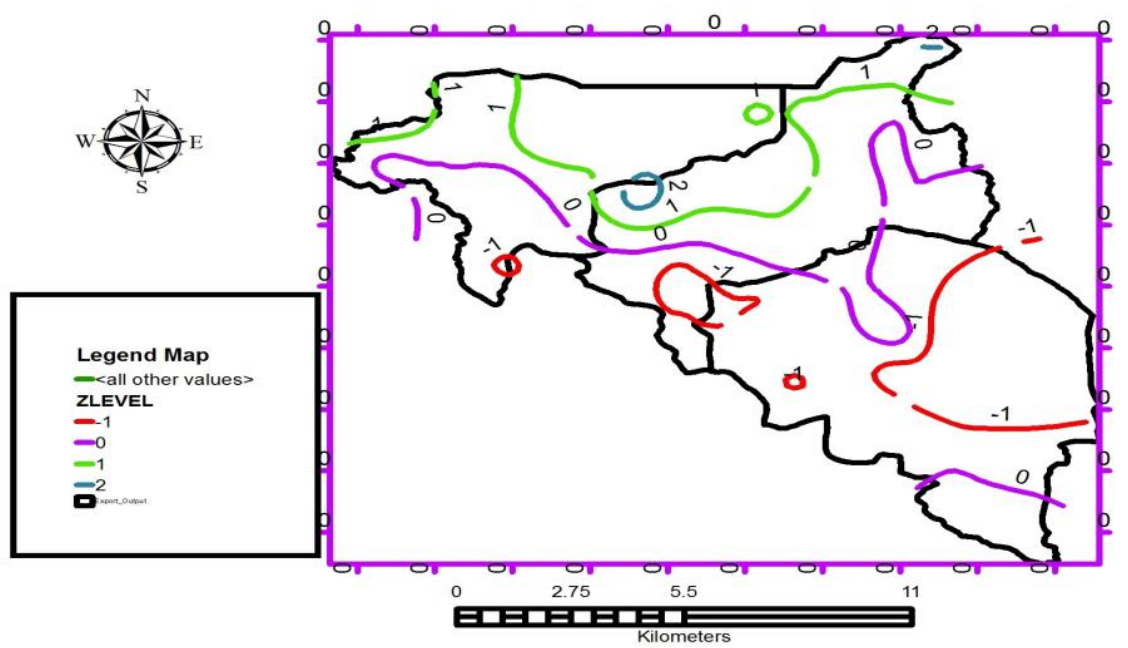

Figure 8. Spatial distribution of partly cloudy and cloudy days factor in the study area 


\section{Radiation factor}

This factor explained $4.62 \%$ of the total variance in primary variables and had strong correlations (>0.7) with number of sunny hours in May-October and annual number of sunny days. Maximum levels of radiation were observed in the northern, northwestern, and eastern parts of Isfahan, Yazd, and Kerman Provinces, respectively (Figure 9).

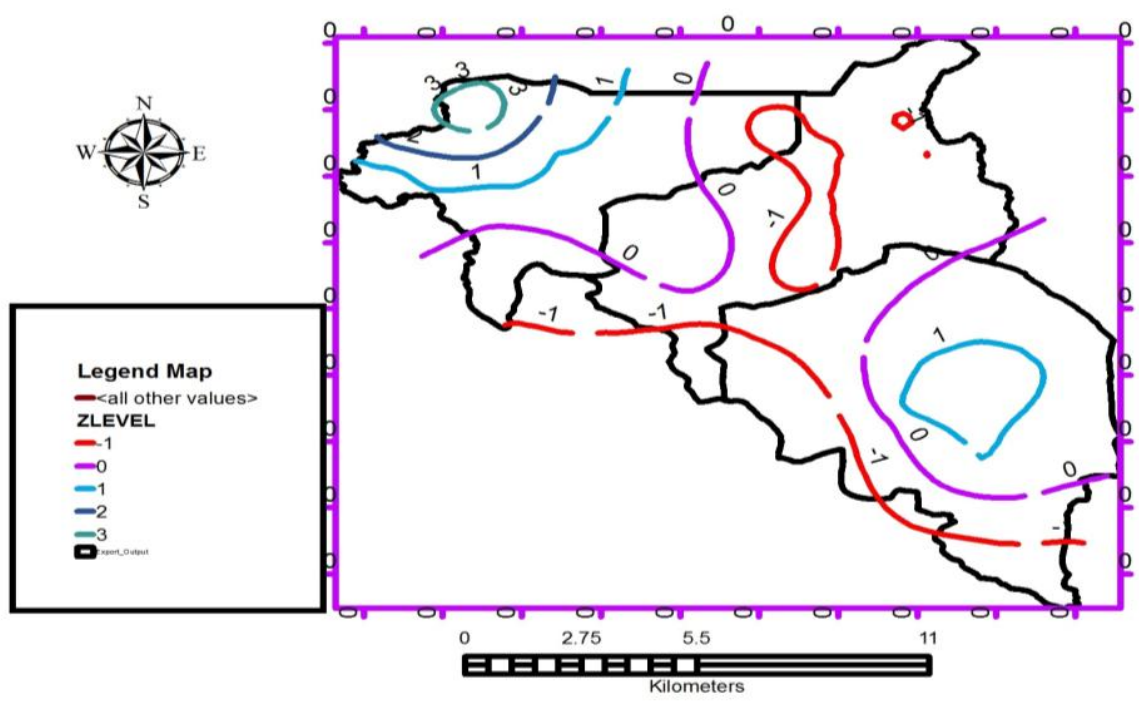

Figure 9. Spatial distribution of radiation factor in the study area

\section{Dust factor}

Dust was the least effective factor in the bioclimatic classification of the study area and explained $3.20 \%$ of the total variance in primary variables. It had strong correlations $(>0.7)$ with number of dusty days in April, May, June, July, and September and annual number of dusty days. As seen in Figure 10, the southwestern parts of Isfahan Province had maximum levels of dust. The eastern and western parts of Yazd Province and the southeastern parts of Kerman Province had the greatest levels of dust in these two provinces.

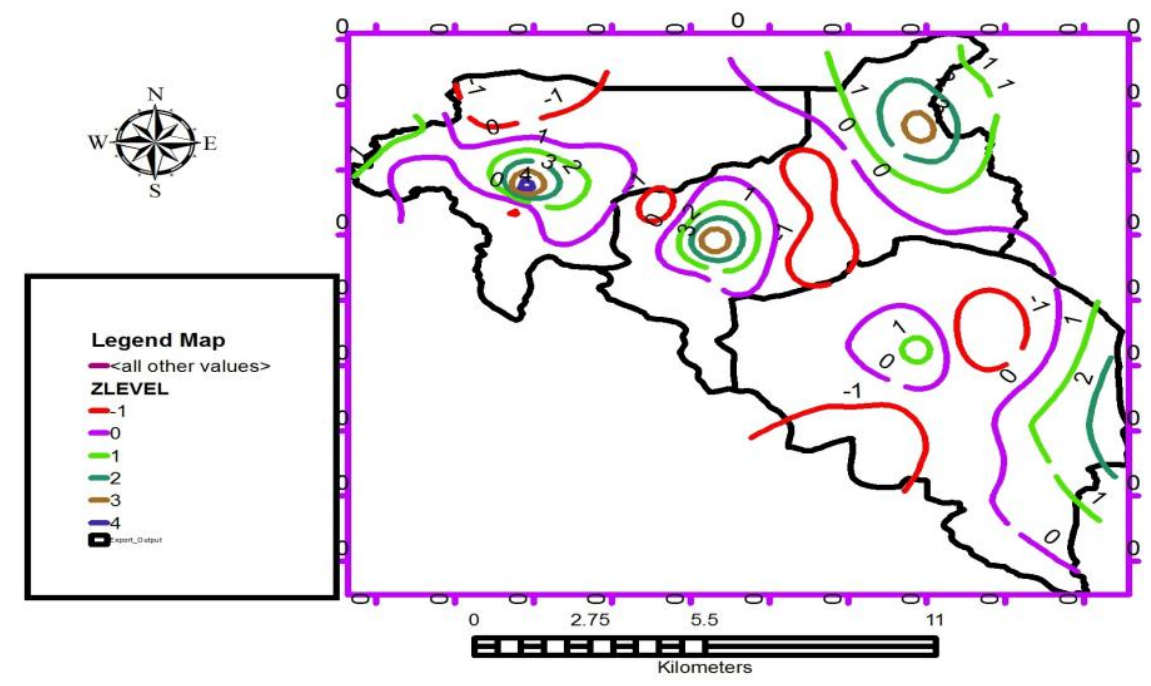

Figure 10. Spatial distribution of dust factor in the study area 


\section{Bioclimatic classification of the study area (central Iran) using multivariate statistical methods}

Cluster analysis is a general term to describe a variety of mathematical methods seeking similarity among a set of observations (Farshadfar, 2001). Cluster analysis has been applied in numerous meteorological studies during the past decades and has progressed significantly since 1990s. Cluster analysis involves various algorithms and methods to classify similar observations based on similarity/dissimilarity criteria. The input into these algorithms is the data required for calculating similarities (Everitt et al., 2005). Using the hierarchical cluster analysis of factor scores based on Ward's method, 13 bioclimatic zones were identified in the study area. Since factor scores show the significance of each factor, the name of each zone was determined based on the sum of factor scores within that zone. Moreover, considering the higher weight of factors 1-3 (discussed in the previous sections), these three factors were mainly used in the naming of bioclimatic zones. Finally, the central areas of Iran were divided into 13 bioclimatic zones (Figure 11), which will be described in the following sections. Climatic classification of the study area was also performed using conventional methods (Figures 12, 13, 14 and 15).

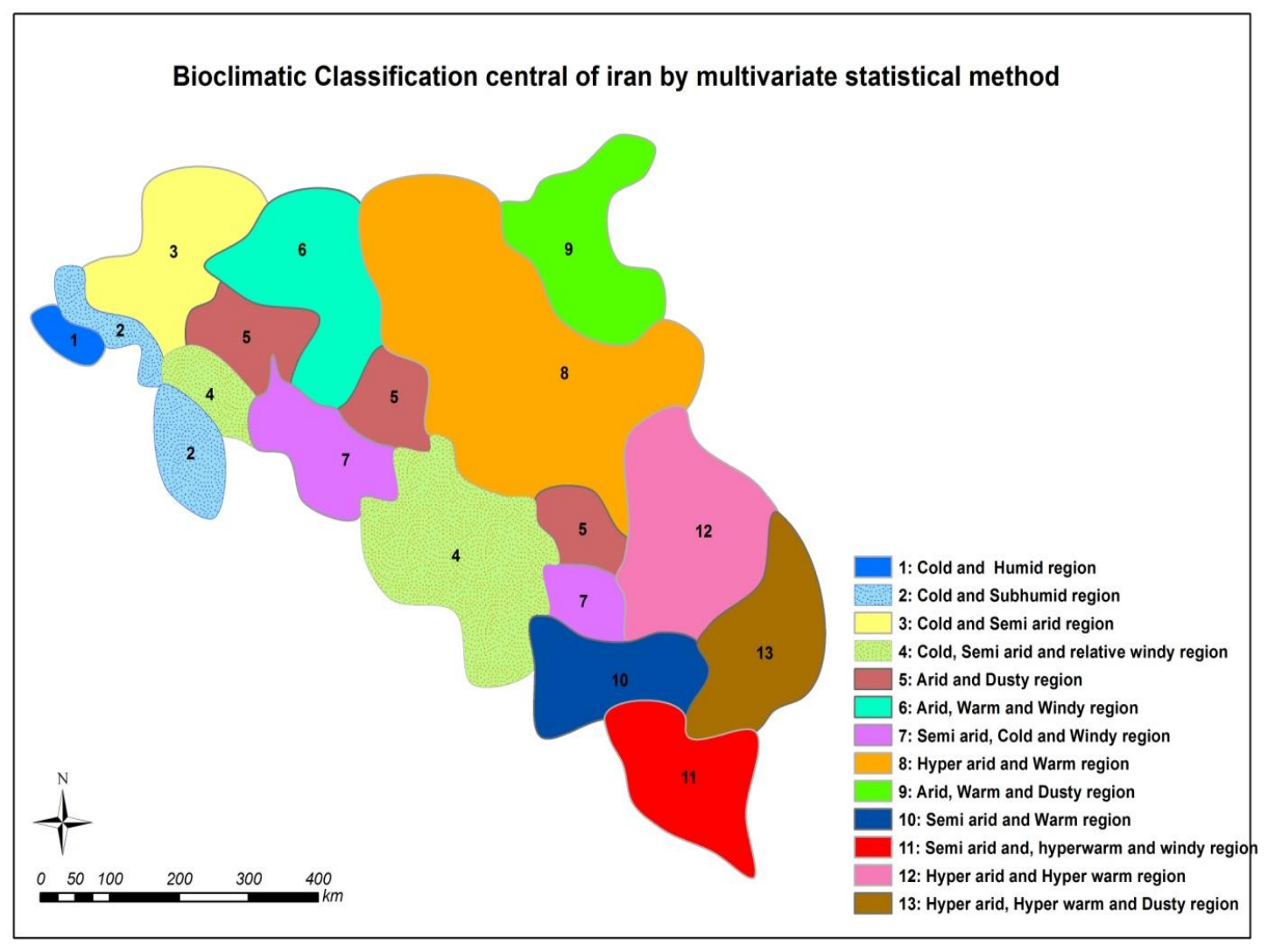

Figure 11. Bioclimatic classification of central Iran by Multivariate statistical methods 


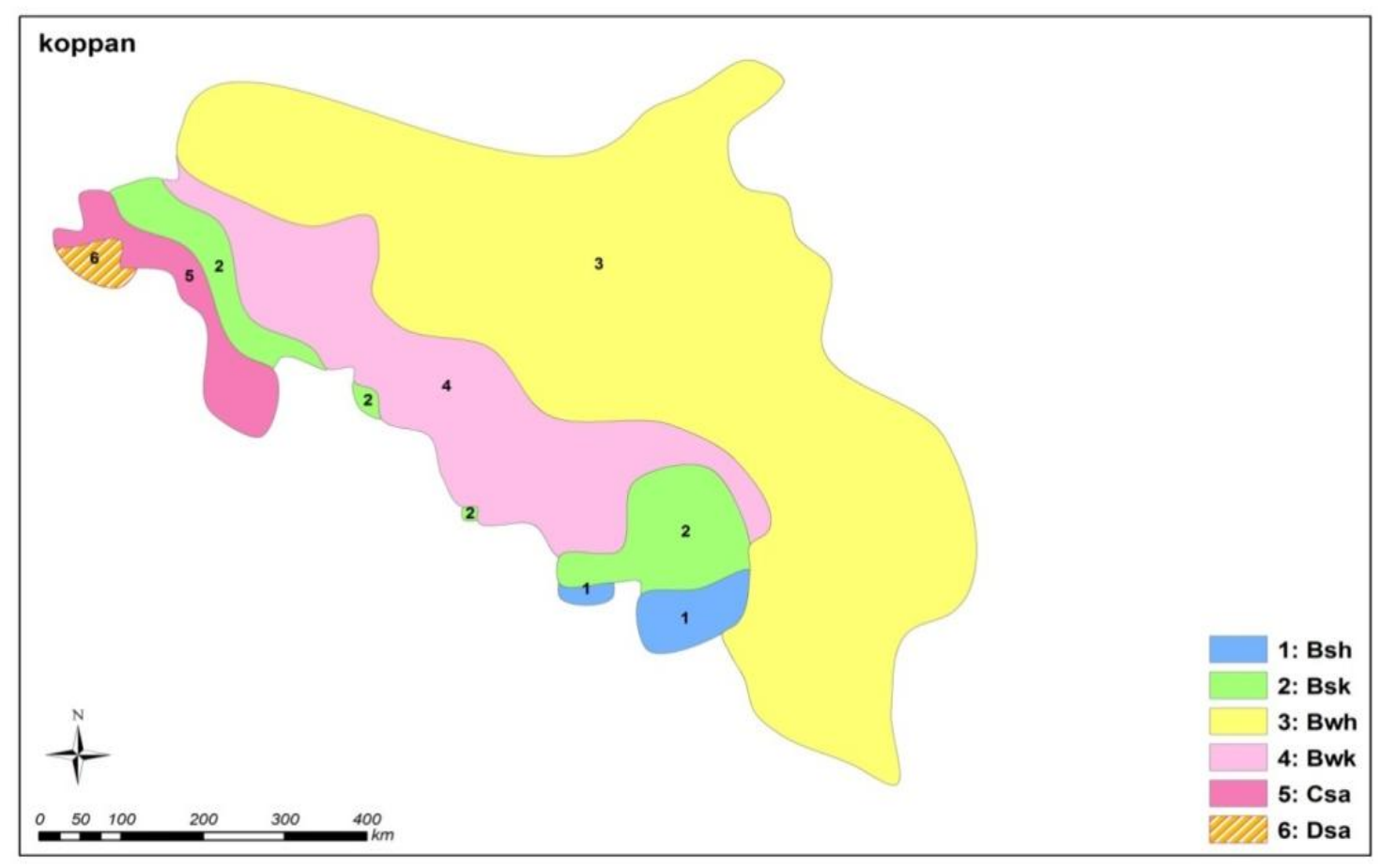

Figure 12. Bioclimatic classification of central Iran by Köppen method

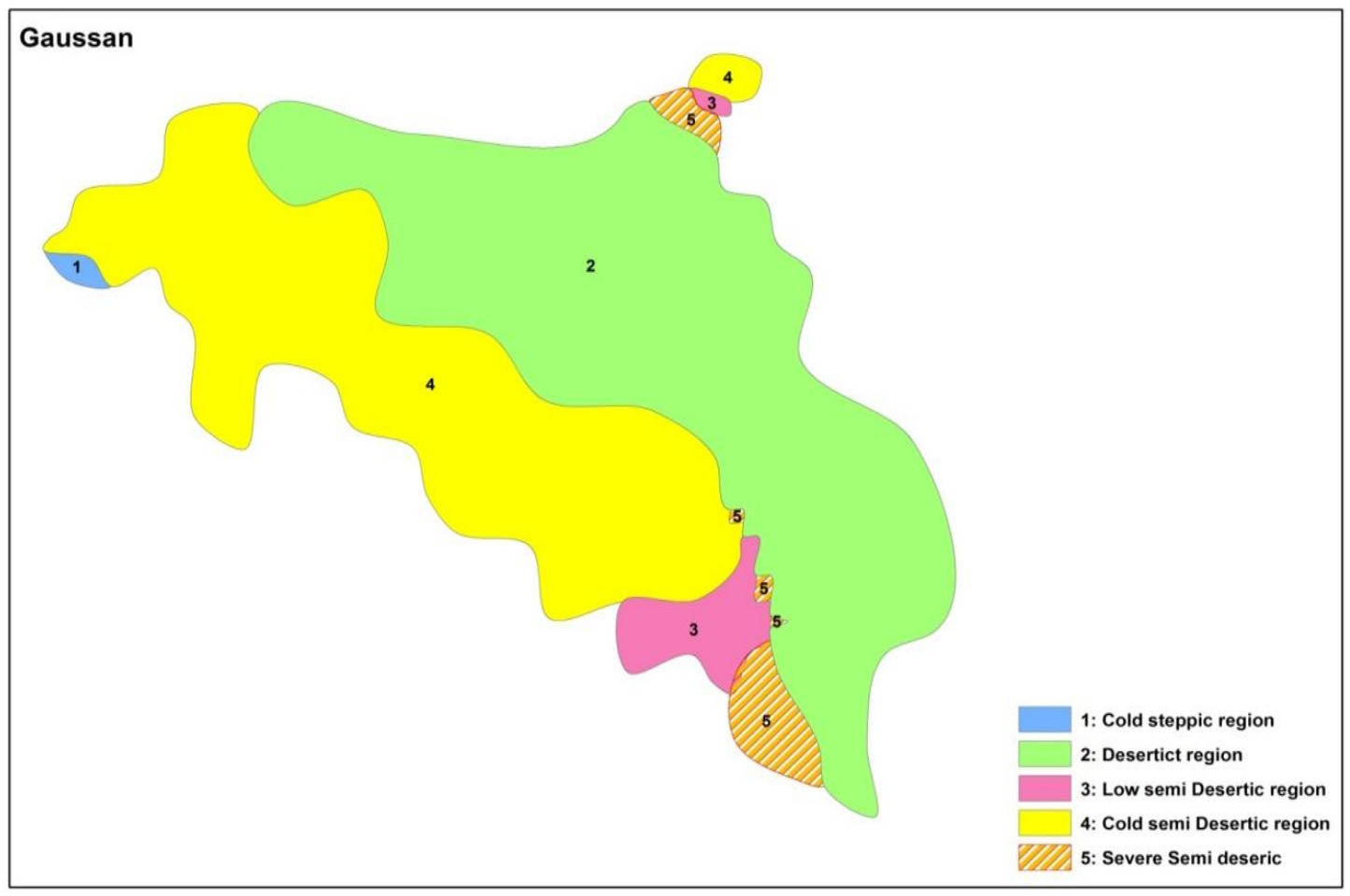

Figure 13. Bioclimatic classification of central Iran by Gaussen method 


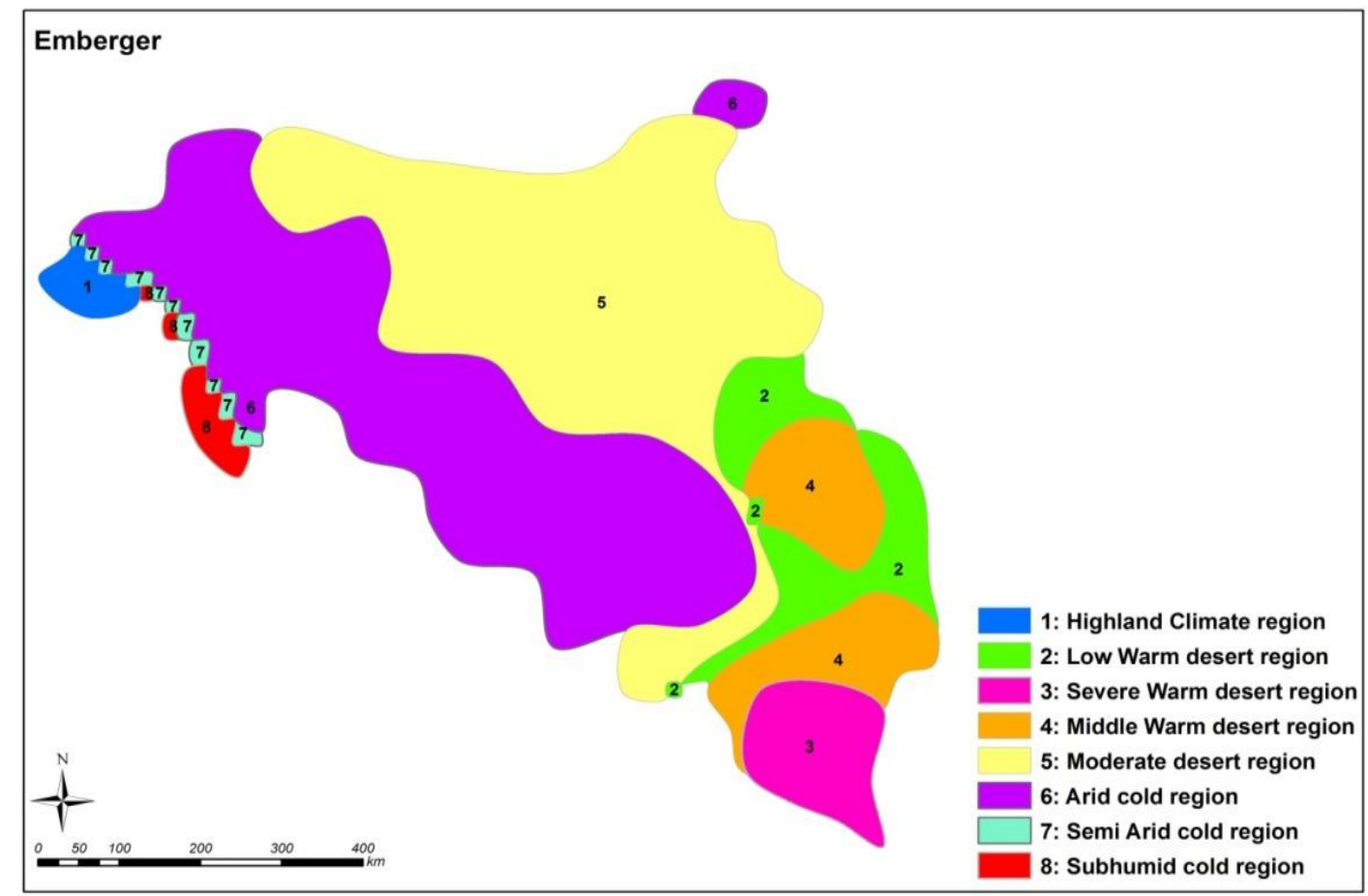

Figure 14. Bioclimatic classification of central Iran by Emberger method

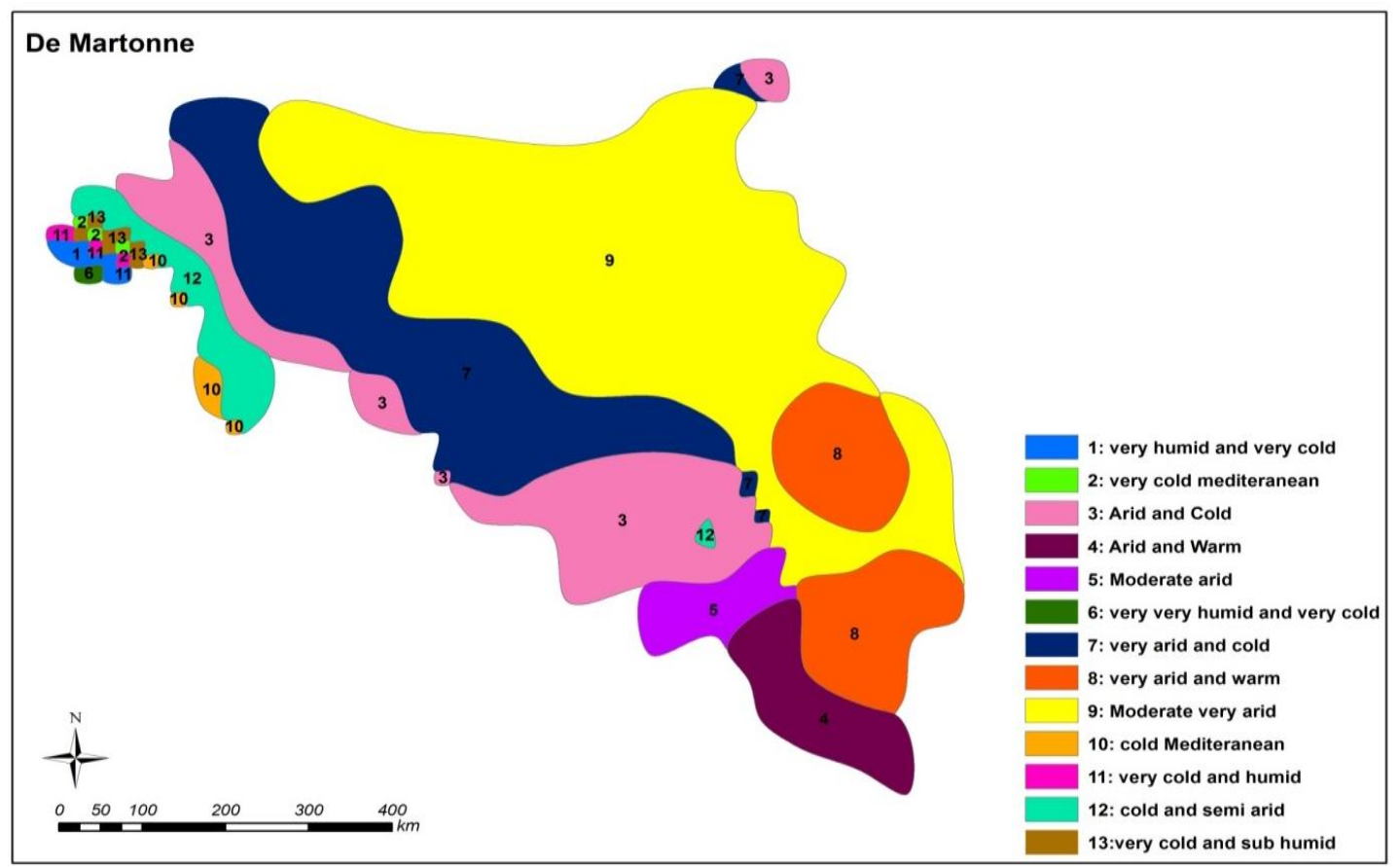

Figure 15. Bioclimatic classification of central Iran by De Matronne method 


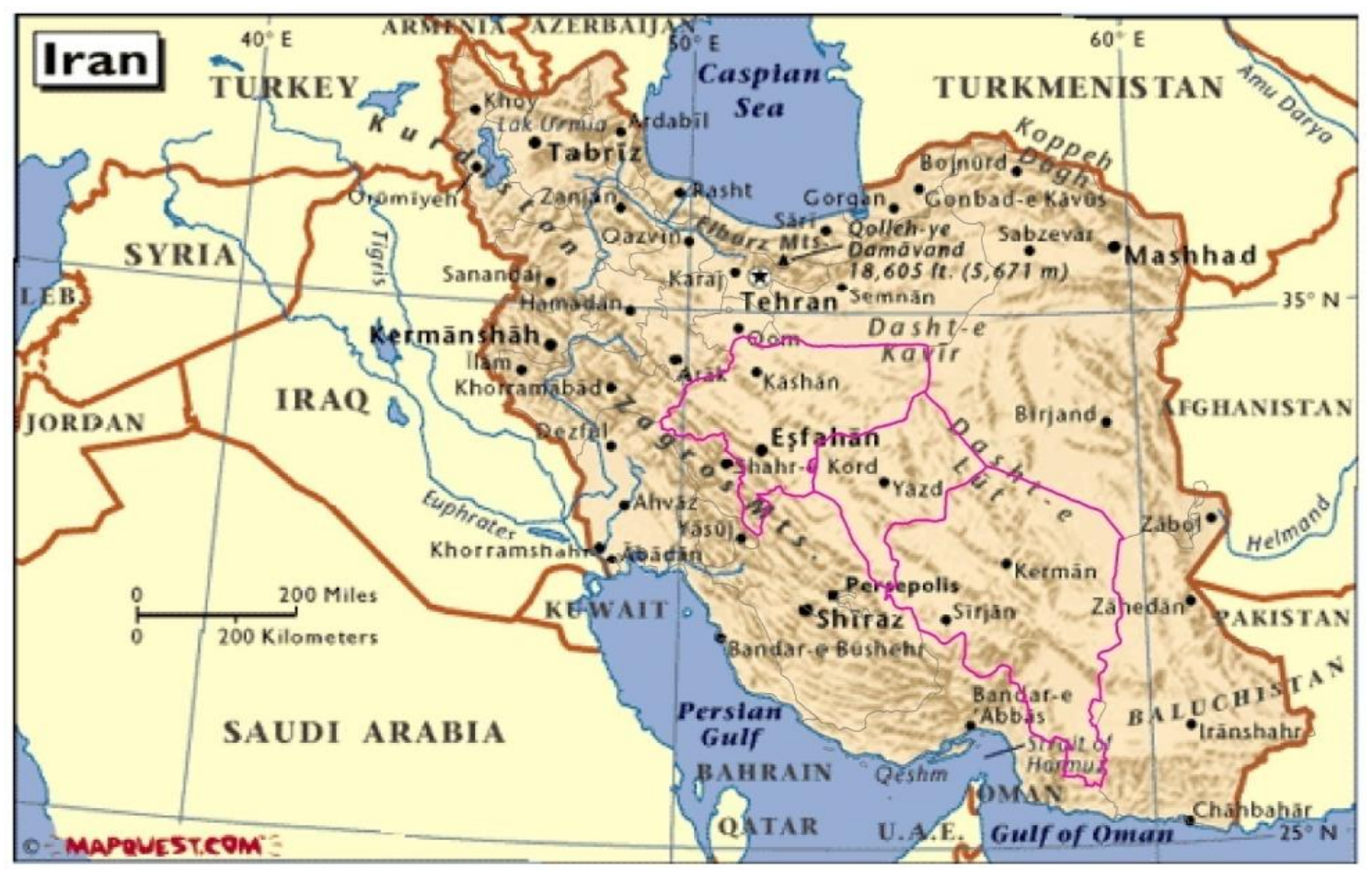

Figure 16. Geographical position of plains (Dasht-e kavir\&Dasht-e Lut), mountains (especially Zagros Mts), seas and study area in Iran

\section{Cold and humid zone}

This zone covered an area of 318,085 ha located only in the western parts of Isfahan Province (Figure 11). The mean altitude, mean annual temperature, and mean annual precipitation of this zone were $1732 \mathrm{~m}$ above the sea level, $10.64{ }^{\circ} \mathrm{C}$, and $831 \mathrm{~mm}$, respectively. Since temperature, spring and cold season rain, and cloudy and partly cloudy days had respectively high negative, high positive, and high factor scores (Table 5), this zone was named "cold". The severe cold, high precipitation, and short growing season in this zone made it suitable for the distribution of specific plant species such as Agropyron trichophorum (Link) Richter. and Astragalus adsendens (Caprini) vereskensis Maassoumi \& Podl. (The dominant species in the area).

According to de Martonne's classification (Figure 15), parts of this zone were, very very humid and very cold and the remaining parts were very humid and very cold. Based on Emberger's classification (Figure 14), the northern and northeastern parts of this zone had Low warm desert and sub-humid cold climates. The remaining parts of this zone were categorized as the highlands climate. This zone had cold steppe climate based on Gaussen's classification (Figure 13) and Csa and Dsa climates based on Köppen's classification (Figure 12). 
Table 5. Factor scores and important climatic variables in thirteen bioclimatic zones in central Iran

\begin{tabular}{|c|c|c|c|c|c|c|c|c|c|c|c|c|c|}
\hline Bioclimatic Zones & I & II & III & IV & $\mathrm{V}$ & VI & VII & VIII & IX & $\mathrm{X}$ & $\mathrm{XI}$ & XII & XIII \\
\hline Average annual temperature & 10.46 & 13.28 & 17.24 & 16.54 & 17.60 & 19.34 & 15.19 & 20.70 & 20.61 & 20.40 & 26.56 & 23.73 & 23.90 \\
\hline $\begin{array}{lll}\text { Average } & \text { annual } & \text { relative } \\
\text { humidity } & & \\
\end{array}$ & 42.89 & 38.73 & 38.26 & 32.75 & 31.53 & 30.20 & 32.14 & 28.79 & 33.27 & 38.65 & 37.48 & 25.21 & 31.20 \\
\hline Annual precipitation & 831.69 & 399.48 & 158.40 & 130.87 & 94.94 & 92.51 & 139.05 & 76.65 & 100.82 & 198.64 & 198.13 & 58.68 & 80.38 \\
\hline $\begin{array}{l}\text { Annual number of days with } \\
\text { dust }\end{array}$ & 7.23 & 9.68 & 16.67 & 14.97 & 32.26 & 22.56 & 13.01 & 24.70 & 37.89 & 13.47 & 26.13 & 26.56 & 41.03 \\
\hline Average annual wind speed & 4.12 & 4.72 & 3.77 & 5.77 & 5.12 & 6.21 & 6.82 & 4.77 & 3.71 & 4.91 & 6.20 & 5.20 & 5.29 \\
\hline Partly cloudy days in annual & 86.59 & 84.41 & 87.78 & 80.89 & 87.73 & 87.13 & 80.30 & 82.26 & 82.41 & 73.34 & 51.40 & 83.28 & 72.72 \\
\hline cloudy days in annual & 38.85 & 29.38 & 35.56 & 24.25 & 31.52 & 34.08 & 24.28 & 29.22 & 29.60 & 17.83 & 13.34 & 15.78 & 16.74 \\
\hline Temperature factor & -0.85 & -1.32 & -0.54 & -1.11 & -0.74 & 0.17 & -1.42 & 0.30 & 0.16 & 0.16 & 2.02 & 1.08 & 0.98 \\
\hline $\begin{array}{l}\text { Relative humidity and warm } \\
\text { season rainfall factor }\end{array}$ & -0.75 & -0.05 & 0.74 & 0.05 & -0.06 & -0.32 & 0.36 & -0.75 & -0.16 & 1.86 & 2.35 & -1.12 & 0.28 \\
\hline $\begin{array}{l}\text { Spring and cool season } \\
\text { rainfall factor }\end{array}$ & 8.03 & 2.71 & -0.17 & -0.36 & -0.46 & -0.17 & -0.47 & -0.19 & -0.08 & -0.04 & 0.50 & -0.01 & -0.08 \\
\hline Wind speed factor & 0.25 & 0.27 & 1.33 & -0.98 & -0.73 & -1.30 & -1.32 & 0.41 & 1.36 & 0.69 & -1.10 & -0.23 & -0.49 \\
\hline $\begin{array}{l}\text { Cloudy and partly cloudy } \\
\text { days factor }\end{array}$ & 0.63 & -0.4 & 0.62 & -0.76 & 0.39 & 1.64 & -0.53 & 0.61 & 0.70 & -0.66 & 0.06 & -1.48 & -1.16 \\
\hline Radiation factor & 0.65 & -0.02 & 2.29 & -0.96 & 0.53 & 0.76 & 0.07 & -0.60 & -0.75 & 0.05 & -0.92 & 0.86 & 0.52 \\
\hline Dust factor & 0.37 & -0.20 & -0.57 & -0.40 & 1.28 & -0.48 & -0.30 & -0.34 & 1.73 & -0.74 & -0.03 & -0.43 & 1.59 \\
\hline
\end{tabular}




\section{Cold and sub-humid zone}

This zone, with the mean altitude of $2510 \mathrm{~m}$ above the sea level, covered an area of $1,328,975$ ha located only in the western and southwestern parts of Isfahan Province (Figure 11). It had different factor scores, i.e. lower precipitation score and very lower negative temperature score, compared to the previous zone. Radiation also had a negative score in this zone. Therefore, it was named as the "cold and sub-humid" zone. The mean annual temperature and precipitation in this zone were $13.28^{\circ} \mathrm{C}$ and 399.48 $\mathrm{mm}$, respectively. Due to its better climatic conditions (e.g. longer growing season), this zone had more diverse vegetation compared to the previous zone. A major difference between the two zones was the presence of Artemisia aucheri Boiss as the dominant plant species in the cold semi-humid zone. Daphne mucronata Royle, Bromus tommentellus Boiss and Astragulus (Caprini) vereskensis Maassoumi \& Podl. were other important species in this zone.

As seen in Figure 15, this zone was categorized as cold and arid, very cold Mediterranean, cold and semi-arid, and very cold and sub-humid based on de Martonne's classification, as cold arid, cold semi-arid, and cold sub-humid based on Emberger's classification (Figure 14), as cold semi-desertic based on Gaussen's classification (Figure 13), and as Bsh (semi-desertic) in Köppen's classification (Figure 12).

\section{Cold and semi-arid zone}

This zone was located solely in the northern and northwestern parts of Isfahan Province. It covered an area of 2,399,222 ha and had a mean altitude of $1735 \mathrm{~m}$ above the sea level (Figure 11). Factor scores of this zone (Table 5) showed considerable reductions in cold and warm season precipitation (compared to the other two zones in this province). While the score of temperature remained almost unchanged, it had a negative score. This zone was hence named as "semi-arid and cold". The mean annual temperature and precipitation in this area were $17.24{ }^{\circ} \mathrm{C}$ and $158.40 \mathrm{~mm}$, respectively. The dominant plant species in this area were Stipa arabica Desf and Artemisia Sieberi Besser.

As Figure 15 shows, this zone was categorized as arid and cold, cold and very arid, and moderate very arid based on de Martonne's classification, as moderate desert and arid cold based on Emberger's classification (Figure 14), as desertic and cold semidesertic based on Gaussen's classification (Figure 13), and as Bsk (or semi desertic), Bwh (or desertic), Csa (or Mediterranean) based on Köppen's classification (Figure 12).

\section{Cold, semi-arid and relatively windy zone}

This zone covered 5,027,126 ha of the western parts of the study area (Figure 11) and had a mean altitude of $1875 \mathrm{~m}$ above the sea level. Temperature had a high negative factor score in this zone. The scores of precipitation were similar in this zone and previous zone (the cold and semi-arid zone) (Table 5). However, considering the high wind speed in this area, wind factor was included in its name and the term "Cold, SemiArid and relatively Windy" was selected for its description. The mean annual temperature and precipitation in this zone was $16.56^{\circ} \mathrm{C}$ and $130.87 \mathrm{~mm}$, respectively. Hammada salicornicum (Moq.) in DC and Zygophyllum eurypterum Boiss. \& Buhse were the dominant species in this zone.

This zone was categorized as cold and arid and very arid and cold based on de Martonne's classification (Figure 15), as cold arid based on Emberger's classification 
(Figure 14), as cold semi-desertic based on Gaussen's classification (Figure 13), and as Bsk (or semi desertic) and Bwk(or desertic) based on Köppen's classification (Figure 12).

\section{Arid and dusty zone}

This zone covered an area of 2,290,305 ha in the western, southeastern, and central parts of the study area (including parts of all three studied provinces) (Figure 11). The mean altitude, annual temperature, and annual precipitation of this zone was $1450 \mathrm{~m}$, $17.60{ }^{\circ} \mathrm{C}$, and $94.94 \mathrm{~mm}$, respectively. According to the Table 5, factor score of precipitation in this zone was substantially lower than those in the above-mentioned zones. In fact, little precipitation was recorded in both cold and warm seasons and precipitation had negative factor scores in all seasons. Since dust had a very higher score in this zone (compared to the other zones), the term "dusty arid" was used to describe this zone. Artemisia Sieberi Besser was the dominant plant species in the area and occupied a large proportion of its lands. The climatic conditions (i.e. very high temperature, radiation, and aridity) and low altitude of this area made it an inappropriate habitat for other plant species such as Artemisia Sieberi Besseri.

This zone was categorized as arid and cold,very arid and cold, and moderate very arid based on de Martonne's classification (Figure 15), as arid cold and semi-arid cold based on Emberger's classification (Figure 14), as cold semi-desertic and desertic based on Gaussen's classification (Figure 13), and as Bwh and Bwk based on Köppen's classification (Figure 12).

\section{Arid, warm and windy zone}

The area covered by this zone $(3,016,687 \mathrm{ha})$ was limited to the eastern and northeastern parts of Isfahan and the north of Yazd Provinces (Figure 11). The mean altitude, annual temperature, and annual precipitation of this zone was $1300 \mathrm{~m}, 19.34$ ${ }^{\circ} \mathrm{C}$, and $92.51 \mathrm{~mm}$, respectively. As seen in Table 5, precipitation (in both warm and cold seasons) had a very low negative factor score. Temperature, Radiation, and cloudy and partly cloudy days had positive scores and were identified as the most significant factors in this "arid and warm" zone. Also, according to Table 5, wind speed variable has a high value in this area therefore, this zone, arid warm and windy were named. The severe ecological and climatic conditions of this zone limited the distribution of plant species. As the dominant species, Artemisia Sieberi Besser comprised 55\% of the vegetation in the hot arid bioclimatic zone. Other species in this zone were Convolvus fraticosa Pall, S. oreintalis, Stipa barbata Desf, and Noeae mucranata (Forsk.) Aschers et Schweinf.

This zone was categorized as very arid and cold, moderate very arid based on de Martonne's classification (Figure 15), as moderate desertic and arid cold based on Emberger's classification (Figure 14), as cold semi-desertic and desertic based on Gaussen's classification (Figure 13), and as Bwh(or desertic) and Csa (or mediteranean) based on Köppen's classification (Figure 12).

\section{Semi-arid, cold and windy zone}

This zone covered an area of 2,453,888 ha, and limited to area south western in Isfahan Province, North West of Yazd and approximately areas in the center of Kerman province (Figure 11). It had a mean altitude, annual temperature, and annual precipitation of respectively $926 \mathrm{~m}, 20.70{ }^{\circ} \mathrm{C}$, and $76.65 \mathrm{~mm}$. The table of factor scores 
shows that temperature had a Negative factor score in this area, the score of warm season precipitation is positive, cold and spring season precipitation were negative scores (Table 5), According to climatic variables in this table (5), we see that wind speed in this zone has high value, therefore this area were named Semi-arid, cold and windy zone. Due to severe climatic conditions, limited plant species, including Callingonum denticulatum Bge. ex Boiss, Zypophyllum eurypterum Boiss. \& Buhse, and Salsola foetida Del, were found in the hot and very arid bioclimatic zone.

As seen in Figure 15, and based on de Martonne's method this zone was categorized as arid and cold, very arid and cold, based on Emberger's method as arid cold (Figure 14), based on Gaussen's method (Figure 13) as cold semi desertic, and based on Figure 12 and Köppen's classification, this zone was categorized as Bsk (or semi-desertic) and Bwk (or desertic).

\section{Hyper arid and warm zone}

This zone covered an area of 8,892,194 ha including parts of East Isfahan Province, East and Northeast of Yazd Province and North area in Kerman province (Figure 11). It had a mean altitude, annual temperature, and annual precipitation of respectively 1246 $\mathrm{m}, 15.19{ }^{\circ} \mathrm{C}$, and $139.05 \mathrm{~mm}$, respectively. This zone owed its name to the very high and positive factor score of temperature, negative factor scores of warm season precipitation and relative humidity, and negative score of cold season precipitation (Table 5). Callingonum denticulatum Bge. ex Boiss., Zypophyllum eurypterum Boiss. \& Buhse, and Salsola foetida Del. were the dominant plant species in this zone.

This zone was categorized as moderate very arid based on deMartonne's classification (Figure 15), as moderate desert region based on Emberger's classification (Figure 14), as desertic region based on Gaussen's classification (Figure 13), and as Bwh based on Köppen's classification (Figure 12).

\section{Arid, warm and dusty zone}

This zone covered an area of 2,784,268 ha in the east of Yazd Province and northeast of the study area (Figure 11). It had a mean altitude, annual temperature, and annual precipitation of respectively $990 \mathrm{~m}, 20.61{ }^{\circ} \mathrm{C}$, and $100.82 \mathrm{~mm}$. While the factor score of temperature was high and positive, factor scores of warm and cold season precipitation showed reductions. Due to the considerable increase in the factor scores of wind speed and dust (Table 5), this zone was named as "dusty, warm, and arid". Because of its severe ecological conditions, only specific plant species, particularly halophytes favored by camels, were found on the sand dunes of this area. Stipagrostis pennata (Trin.) De Winter, Haloxylon persicum (Moq.) in DC, and Seidlitzia rosmarinus (Ehrenb.) Bge were the dominant plant species in this zone.

This zone was categorized as moderate very arid, cold and very arid, arid and cold ,based on de Martonne's classification (Figure 15), as arid cold and moderate desert based on Emberger's classification (Figure 14), as desertic, low semi-desertic, cold semi-desertic, and severe semi-desertic based on Gaussen's classification (Figure 13), and as Bwh (or desertic) based on Köppen's classification (Figure 12).

\section{Semi-arid and warm zone}

This zone covered an area of 2,178,543 ha (with a mean altitude of $1710 \mathrm{~m}$ ) on the southwest of Kerman Province (Figure 11). The most important factor in this zone was 
temperature (which had a positive factor score). While cold season precipitation had a low negative factor score, relative humidity and warm season temperature had very high positive factor scores (probably due to the proximity of the area to the Persian Gulf and Oman Sea in the south of Iran). Therefore, the term "hot, semi-arid" was used to describe this zone (Table 5). The mean annual temperature and precipitation in this zone were $20.40{ }^{\circ} \mathrm{C}$ and $198.64 \mathrm{~mm}$, respectively. Hammada salicornicum (Moq.) and Salsola foetida Del. were the dominant plant species in this zone.

This zone was categorized as moderate arid, arid and cold, moderate very arid, warm and arid, and very arid and warm based on de Martonne's classification (Figure 15), as arid cold, moderate desert, middle warm desert, and low warm desert based on Emberger's classification (Figure 14), as desertic, severe semi-desertic, cold semidesertic, and low semi-desertic based on Gaussen's classification (Figure 13), and as Bwh(or semi desertic), Bsk, and Bsh(or desertic) based on Köppen's classification (Figure 12).

\section{Semi-arid, hyper warm and windy zone}

This zone was located at the southernmost part of the study area and covered an area of 2,215,759 ha (Figure 11). The data in Table 5 shows that the proximity of this climatic zone to the Persian Gulf and Oman Sea (huge water resources) affected all climatic factors, especially relative humidity, temperature, and warm season precipitation (which gained high positive scores). Considering the scores of other factors, particularly cold season precipitation, and the wind speed in Table 5, the term "Semi-Arid, hyper warm and windy" was used to name this zone. The mean altitude, annual temperature, and annual precipitation of this zone were $722 \mathrm{~m}, 26.56^{\circ} \mathrm{C}$, and $198.13 \mathrm{~mm}$, respectively. The dominant plant species of this zone were Salsola foetida Del, Tamarix deserti Boiss, and Seidlitzia rosmarinus (Ehrenb.) Bge.

This zone was categorized as arid and warm, very arid and warm based on de Martonne's classification (Figure 15), as severe warm desert based on Emberger's classification (Figure 14), as desertic and severe semi-desertic based on Gaussen's classification (Figure 13), and as Bwh (or desertic) based on Köppen's classification (Figure 12).

\section{Hyper arid and hyper warm zone}

This zone, covering an area of 3,805,215 ha, was located in the southeastern part of the study area (Figure 11). It had a mean altitude, annual temperature, and annual precipitation of $928 \mathrm{~m}, 23.73{ }^{\circ} \mathrm{C}$, and $54.68 \mathrm{~mm}$, respectively. While temperature had a high positive factor score in this zone, scores of warm and cold season precipitation were low and negative. Moreover, Radiation had a positive score, but the scores of cloudy and partly cloudy days and wind speed were negative (Table 5). This zone was hence named as "Hyper arid and hyper warm". The severe ecological and climatic conditions of the area justified the sparsity and very limited diversity of plant species (the plants grew in long distances from each other). The dominant species in this zone were Sueadea fruticosa (L.) Forsk., Salsola crassa M.B. in Mem., and Seidlitzia rosmarinus (Ehrenb.) Bge.

This zone was categorized as very arid and warm, moderate very arid based on de Martonne's classification (Figure 15), as low warm desert, middle warm desert, moderate desert and arid cold, based on Emberger's classification (Figure 14), as 
desertic based on Gaussen's classification (Figure 13), and as Bwh and Bwk (or desertic) based on Köppen's classification (Figure 12).

\section{Hyper arid, hyper warm and dusty zone}

This zone covered an area of 206,704 ha situated at a mean altitude of $818 \mathrm{~m}$ above sea level (Figure 11). According to Table 5, it can be seen that the factor score of temperature has high and positive score (close to one) in this zone; cold season precipitation has a very low negative score. Relative humidity and warm season precipitation has very low positive scores. In contrast, dust obtained a high positive score. The positive score of Radiation suggested that high levels of solar Radiation reached the earth in this area. Therefore, this zone was described as "Hyper arid, hyper warm and Dusty". Due to the severe climatic conditions (mean annual temperature and precipitation equal to $23.90{ }^{\circ} \mathrm{C}$ and $80.38 \mathrm{~mm}$, respectively) limited plant species, including Salsola longifolia Forsk., Haloxylon ammodendron (C.A.Mey.) Bge, and Tamarix kotschyi Bge., grew in this area.

This zone was categorized as very arid and warm, and moderate very arid based on de Martonne's classification (Figure 15), as low warm desert and middle warm desert based on Emberger's classification (Figure 14), as desertic based on Gaussen's classification (Figure 13), and as Bwh (or desertic) based on Köppen's classification (Figure 12).

\section{Discussion and Conclusion}

According to the results obtained in this study, from among climatic factors, the following 7 factors: temperature, relative humidity and rainfall in the hot season, rainfall in spring and the cold season, wind speed, cloudy and partly cloudy days, solar radiation, and dust and mist play a major role in the distribution of plant species habitats in the study area. These factors allocate $28.45 \%, 20.43 \%, 17.13 \%, 9.13 \%, 8.03 \%$, $4.62 \%$ and $3.20 \%$ of the total variance to themselves, respectively, which makes $91.01 \%$ in total. These findings are consistent with the studies conducted by other researchers such as Torabi et al. (2001), Domroes et al. (1998), Tan et al. (2002), and Hossel et al. (2003). For example, Unal et al. (2003) defined the climatic areas of Turkey by using mathematical methods of cluster analysis. The research data from 113 climate stations from 1951 to 1998 were used for temperature (average, minimum and maximum) and total precipitation. In addition, the hierarchical cluster analysis was selected for classification. In this study, five different techniques were primarily implemented to determine the most appropriate method for the region, and it was concluded that the Wards Method has the best and most acceptable results. Finally, seven climatic areas were obtained. Yaghmaie et al. (2009) investigated the bioclimatic classification of Isfahan Province using multivariate statistical methods. The results of their study showed that the three factors: precipitation, temperature, and solar radiation are the most important factors in the distribution of vegetation in Isfahan. Seven bioclimatic classifications were identified in this study using the factor analysis and cluster analysis techniques, and predominant vegetation types were introduced in each climate.

Estrada et al. (2009) defined the climatic areas in Mexico City using the multivariate analysis. In this study, multivariate methods were used to reduce the dimensions of the variables reported by meteorological stations. In addition, by using multivariate 
statistical methods, we dealt with defining climate indices, showing main climatic factors, and introducing geographical areas with similar climatic characteristics. Then, 2 broad climatic areas and 4 climatic sub-areas were defined, and finally it was concluded that using multivariate analysis methods can be a useful tool for urban planning.

In general, in this study and according to the table of factor scores (Table 5), it can be understood that temperature has allocated the highest percentage of variance to itself among other climatic factors, and has the highest positive scores and impact in zones 12 and 13 in the south-eastern parts of the study area. Moreover, the highest negative score is related to the temperature of zones 2, 4 and 7, which are located in the western and south-western parts of the study area; the areas which have been called cold semi-arid, relatively windy, and cold sub-humid. Whereas in zones 12 and 13, the factor scores of precipitation in the hot and cold seasons are negative and low. On the other hand, the factor scores of dust and mist and solar radiation are positive and high, which indicates that in these zones, the role of precipitation in the distribution and dispersion of plants is much lower than that of temperature. However, in zone 12, relative humidity and precipitation in the hot season are high and positive. This is mainly related to the high level of relative humidity in this area, rather than precipitation in the hot season, which is because this zone is close to the Persian Gulf and the Sea of Oman (Fig. 16) where relative humidity is very high. Whereas in zones 1 and 2 the factor score of precipitation is the highest amount possible among the climatic zones, and this indicates that in these two zones the role of the factor precipitation (in the warm and cold seasons) is much more important in the distribution and dispersion of plants than that of other factors. In addition, since zones 12 and 13 are near Dasht-e Lut (Fig. 16), these areas have a very warm and arid climate, which has affected the climatic characteristics of these two areas. For example, the degree of the factor dust is high in zone 12, and this factor has had a significant effect on the designation of this zone. In addition, because Dasht-e Lut is very close to these two zones, the ecological climatic conditions governing these two zones are very hard and difficult. Hence, the diversity of plant species is low in these two zones, and species of the genera seidlitzia, salsola, Haloxylon, and Tamarix, which can only grow in these areas, are found there. In zones 4, 6, 7 and 12, the degree of the factor wind speed is high. Moreover, when we look at the table of factor scores (Table 5 ), we realize that the degree of the factor wind speed is high in the above-mentioned zones, and it is considered an influential and effective factor in the distribution of vegetation in these zones. Hence, this factor has been used in the designation of these zones. In general, when we look at the results of classification by using multivariate statistical methods in this study, we find out that a very precise climatic classification has been done according to the climatic and ecological conditions governing each zone. Such that by hearing the climate's name in each zone, a researcher, in the first place, obtains a very detailed general idea about that climatic area, and this is one of the advantages of the multivariate statistical technique, which is very complete and accurate. Moreover, the climatic classification of the study area using some common climatic methods (Köppen, Gaussan, De Marton, and Emberger) indicates the inability of these methods to separate climatic areas compared to the multivariate statistical method; whereas the multivariate statistical method has a high ability to separate climatic areas. For example, due to their proximity to Dasht-e Kavir and Kavir-e Lut (Figure 16), zones 6, 8, 9, 12 and 13 are warm, and the heat of the desert has also affected these zones. In addition, according to the map of Figure 16, as we can see, zones 10 and 11 are attached to huge sources of water (the Persian Gulf and the Sea of 
Oman), the relative humidity is high and the weather is warm and humid in these areas, and they affect their adjoining areas. Therefore, zone 10 is called semi-arid and warm, and zone 11 is called semi-arid and very warm. In addition, as shown in the map of Fig. 16, since they are located near the Zagros Mountain Range, zones 1 and 2 have cold and rainy winters. Moreover, due to their being located in the highlands, they are cold with very low temperatures. Hence, they have been called humid cold and cold, sub-humid. As we know, mountain ranges, plains, deserts (topography), and water resources are effective in the development of climates, and affect them. Hence, according to the results obtained from the multivariate statistical method, all the 13 climatic zones in this study have been obtained separately and according to the ecological-climatic conditions governing them (as shown in the map of Fig. 11). On the other hand, the traditional methods of climatic classification, which are mainly used (Köppen, Gaussen, Emberger, and De Marton), are incapable in this regard, and do not have great accuracy in separating the Bioclimates. For example, in this study, as shown in Figure 13, more than $95 \%$ of the study area has been allocated to two zones; desertic and cold semidesertic, in the Gaussen method. In this method, about $50 \%$ of the entire area has been allocated to the desertic zone (Figure 12). Whereas, in the multivariate statistical method, this area has been divided into 6 different climatic zones; namely, (windy warm arid, dusty arid, warm very arid, dusty, warm, arid, very warm very arid and dusty ,very warm , very arid). In addition, in the Gaussen method, the cold semi-desertic zone has allocated an area equivalent to about $45 \%$ of the entire region (the map of Figure 13) to itself. However, in the multivariate statistical method, this same zone has been divided into 5 different and separate climatic zones; namely, (cold and sub-humid, relatively windy cold and semi-arid, cold and semi-arid, dusty and arid, windy cold and semiarid). This indicates the high ability of the multivariate statistical method to separate the Bioclimates. In addition, in the Köppen method, as shown in the map of Fig. 12, zones 3 and 4, which have been called Bwh and Bwk or desert climate, have allocated an area equivalent to about $70 \%$ of the entire region to themselves. Whilst, according to the multivariate statistical method, zone 3 or Bwh has been divided into 7 different climatic zones, namely dusty arid, windy warm arid, warm very arid, dusty warm arid, windy very warm semi-arid, very warm very arid, and dusty very warm very arid. Also, zone 4, called Bwk or desert zone in the Köppen method, has been divided into 4 different and separate climatic zones, namely cold semi-arid, relatively windy cold semi-arid, dusty arid, and windy cold semi-arid, in the multivariate statistical method. They are in accordance with the climatic and ecological conditions governing each zone and affect the plant species in each zone, again indicating the high ability of the multivariate statistical method to separate the Bioclimates. The two methods, Emberger and De Marton, have carried out a better classification than the previous methods (Köppen and Gaussan), Köppen and Gaussan, did; nevertheless, some climatic areas (considering their climatic parameters) are still far from reality. For example, in the Emberger method, the cold arid climatic zone and the moderate desert climatic zone have allocated $90 \%$ of the entire region to themselves (Fig. 14). The region which has been called cold arid according to the Emberger method (the northeastern part of the study area) is not a cold region at all. Rather, it is quite warm (close to Kavir-e Lut and Dashte-Kavir, which are considered the hottest points in Iran, map of Figure 16), and this is quite far from reality and it is one of the weaknesses of the Emberger method. In addition, according to the Emberger method, the moderate desert zone has allocated a broad area to itself (Fig. 14). While this region is not considered a moderate region at 
all; rather, it is quite warm (according to the climatic parameters of this area). Moreover, in the multivariate statistical method, this broad area, itself, has been divided into 5 smaller and more accurate climatic zones. Such that the climatic factors; wind speed, and dust, were effective in the separation of these five climatic areas, and have made their designation match the climate realities, again indicating the inability and inefficiency of the Emberger method in the correct separation of the bioclimates. In addition, with regard to the De Marton method, even though it has correctly classified the climates in some parts (especially the western parts of Isfahan Province), it has some weaknesses, too. For example, the area it has called cold arid climatic zone, just as it was called in the Emberger method (the northeastern part of the study area), is not a cold area at all; rather, it is quite warm, and this is considered one of the weaknesses of this method in separating the climates. In addition, the zone called (cold and very arid) in this method has been divided into three different climatic zones; namely, (cold and semi-arid, dusty and arid, windy cold semi-arid) in the multivariate statistical method. According to Table 5 and considering their climatic characteristics, regions or zones 3 , 5 and 7, which have precipitations of $158 \mathrm{~mm}, 94.94 \mathrm{~mm}$, and $139.05 \mathrm{~mm}$, respectively, are not considered hyper-arid areas. Considering their climatic characteristics according to Table 5, these zones are called (semi-arid, arid and semi-arid areas) rather than hyperarid areas, which is also one of the weaknesses of the De Matron method in separating the climatic areas. Also, in this method (De Matron), the moderate very arid climatic zone, first: has allocated a broad area to itself, whilst this same zone has been divided into 4 zones in the multivariate statistical method. Second: designation of this zone as moderate very arid is completely far from the climatic fact of this region. As mentioned earlier, the multivariate statistical method has divided this zone into 4 sub-zones (windy warm arid, dusty and arid, warm and hyper arid, dusty and warm arid), which has been done based on the statistical facts of the climates of each zone. According to Table 5, the precipitations of these 4 zones are $94.94 \mathrm{~mm}, 92.51 \mathrm{~mm}, 100.82 \mathrm{~mm}$, and 198.13 $\mathrm{mm}$, respectively. If we assume that these four zones are one zone, the mean precipitation in this zone will be $121.60 \mathrm{~mm}$, and taking into account this amount of precipitation, designation of this zone as hyper-arid, as it was done in the De Matron method, is far from the reality. On the other hand, the De Matron method has called this zone moderate. Since it is located in central Iran, and these regions are warm and even very warm, the multivariate statistical method has called these zones warm according to Table 5. In addition, when we look at the annual temperature of these four zones (zones $5,6,8$, and 9 in the multivariate statistical method); we find that it is close to reality. In general, this research shows the ever-greater efficiency of multivariate statistical methods in determining the magnitude of each climatic factor in the distribution and dispersion of plant species and in determining different climatic zones in central Iran (including the 3 provinces of Kerman, Yazd, and Isfahan) in comparison to conventional and traditional climatic classification methods. Moreover, in the climatic classification of Saudi Arabia, using multivariate statistical methods, factor analysis, and cluster analysis; and comparing it with classical climatic classification methods such as Gaussen and De Matron, Ahmed, too, came to the conclusion that multivariate statistical methods have divided this country into nine different climatic zones. However, the classical methods have divided the whole country of Saudi Arabia into 2 or 3 regions. In addition, he finally concluded that the diversity of climatic variables used in multivariate statistical methods makes this climatic classification method seem much more useful than classical and traditional methods (Ahmed, 1997). In general, the 
predominant rangeland and forest species of each climatic zone is consistent with the climatic conditions of that area. For example, the species of the genera H. Salicornica, which are the predominant species of the warm, dusty and arid climatic areas, are consistent with the climatic conditions of this region. In the present study, a climatevegetation classification was conducted on a large scale in central Iran (including the three provinces of Kerman, Yazd and Isfahan), which only considered the effect of the macroclimate on the vegetation. In the end, it is suggested that more factors such as topography and soil are considered in the study of the climatic regions of vegetation distribution in order to improve the results of the bioclimatic classification. Nevertheless, this study paves the way for the next bioclimatic studies.

\section{REFERENCES}

[1] Ahmed, B. (1997): Climatic classification of Saudi Arabia: an application of factorcluster analysis - GeoJournal 41(1):69-84.

[2] Amigo, J, Ramirez, C.( 1998): A bioclimatic classification of Chile - Plant Ecology 136: 9-26.

[3] Belasco ,F. (1988): The International Vegetation Map (Toulouse, France) - Vegetation mapping, Handbook of vegetation science 10: 443-460.

[4] DeGaetano, A.T., Schulman, M.D. (1990): Climate classification of plant hardiness in the United States and Canada - Theoretical and Applied Meteorology 61: 151-159.

[5] Dinpazhouh, Y.S., Jahanbakhshasl (2003): Climatic zoning of Iran using multivariate analysis to be used in agricultural studies - Journal of Agricultural Science 13:71-90.

[6] Domroes, M., Kaviani, M., Schaefer, D.(1998): An analysis of regional and intra-annual precipitation variability over Iran using multivariate statistical methods - Theoretical and Appl. Meteorol. 61:151-159.

[7] Estrada, F., Martinez, A., Fernandez, A., Luyando, E., Gay, C.( 2009): Defining climate zones in Mexico City using multivariate analysis - Atmosfera 22(2): 175-193.

[8] Everitt, B., Landau, S., Less, M. (2001): Cluster Analysis - 4th ed: Arnold, London

[9] Farshadfar, E. (2001): Multivariate Principal and Procedures of Statistics - Taghebostan Publication: Kermanshah, Iran.

[10] Gavilán ,R. G. (2005): The use of climatic parameters and indices in vegetation distribution. A case study in the Spanish Sistema Central - International Journal of Biometeorology 50(2):111-120.

[11] Gerami Motlagh, A., Shabankari, M. (2006):Climatic zoning of Bushehr Province Research journal of human science in Isfahan university (20):187-210.

[12] Hossell, J.E., Riding, A.E., Brown, I. (2003): The creation and characterization of a bioclimatic classification for Britain and Ireland - Journal for Nature Conservation (Elsevier) 11(1): 5-13.

[13] Jafarpour, A. (2000): Climatology-Tehran University Press, 382 p.

[14] Javanshir, K. (1975): Atlas of Iran woody plants - published by society of natural resources and human environment conservation.

[15] de Sá Júnior, A., de Carvalho, L. G., da Silva, F. F., de Carvalho Alves, M. (2011): Application of the Köppen classification for climatic zoning in the state of Minas Gerais, Brazil - Theoretical and Applied Climatology 108(1): 1-7.

[16] Kaviani, M., Masoudian, A. (1999): Climate of Iran - Isfahan University Press.

[17] Khodagholi, M. (2005): Bioclimatic survey of Zayanderood basin. PhD thesis - Faculty of humanity science, Isfahan University.

[18] McGregor, G. R. (1993): A Multivariate Approach to the Evaluation of the Climatic Regions and Climatic Resources of China-Geoforum 24: 357-380. 
[19] Masoudian, A. (2003): Climatic region of Iran - Journal of Geography and Development 1(2):171-184.

[20] Ndetto, E., Matzarakis, A. ( 2013): Basic analysis of climate and urban bioclimatic of Dar es Salaam, Tanzania - Theoretical and Applied Climatology 114: 213-226.

[21] Pabout ,H. (1979): Bioclimatic classification of Iran rangelands using rainfall and temperature data - Research Institute of forests and rangelands of Iran

[22] Pedrotti, F. (2012): Types of Vegetation Maps - In: Pedrotti, F. (ed) Plant and Vegetation Mapping (part of the series Geobotany Studies), $6^{\text {th }}$ chapter, pp. 103-181., SpringerVerlag, Berlin, Heidelberg.

[23] Peinado, M., Alcatraz., F., Aguirre, J. L., Martínez-Parras, J.M. (1997): Vegetation formations and associations of the zonobiomes along the North American Pacific coast: from northern California to Alaska - Plant Ecology 129: 29-47.

[24] Retuerto, R., Carballeira, R. ( 1992): A Use of direct gradient analysis to study the climate vegetation relationships in Galicia, Spain - Plant Ecology 101(2): 183-194.

[25] Sabeti, H. (1962): Relationship between Plant and Environment (Syn- Ecology) - Tehran University Publication: Tehran, Iran.

[26] Sabeti, H. (1969): Climatic region of Iran - Tehran University Publication: Tehran, Iran.

[27] Saligheh, M.B., Faramarz, M., Nezhad, E. (2008): Climatic zoning Sistan and Baluchistan province - Journal of Geography and Development 12:101-116.

[28] Seyedan, S.J., Mohammadi, F. ( 1997): Methods of climatic classification - Journal of Geographical Research 45: 74-109.

[29] Soltani, S., Yaghmaei, L., M., Khodagholi, M., Sabouhi, R. (2011): Bioclimatic classification of Chaharmahal \& bakhtiari province using multivariate statistical methods - Journal of Science and Technology of Agriculture and Natural Resources, Soil and Water Sciences (JWSS-Isfahan University of Technology) 14 (54): 53-68.

[30] Tan, S. (2002): Modeling Spatial Patterns of Vegetation Activity and Climatological in the U.S Great Plain - Department of Geography, University of Cambridge: London.

[31] Torabi, S., Jahanbakhsh, S., Alijani, B., Shafiei, K.H. (2001): Iran climatic classification, Multivariate analysis methods - Quarterly Geographical Studies 39:90-95.

[32] Unal, Y., Kidnap, T., Karaka, M. (2003): Redefining the climate zones of Turkey using cluster analysis - Intl. J.Climatol. 23(99):1045-1055.

[33] Yaghmaei, L., Soltani, S., Khodagholi, M. (2009): Bioclimatic classification of Isfahan province using multivariate statistical methods - Intl. J. Climatol. 29:1850-1861.

[34] Yurdanur, U., Tayfun, K., Mehmet,K. (2003): Redefining the climate zones of turkey using cluster analysis. - International Journal of Climatology 23(9): 1045-1055.

\section{APPENDIX}

KMO and Bartlett's Test

\begin{tabular}{|l|r|}
\hline $\begin{array}{l}\text { Kaiser-Meyer-Olkin Measure of Sampling Adequacy. } \\
\text { Bartlett's Test of Sphericity } \quad \text { Approx. Chi-Square }\end{array}$ & .985 \\
& df \\
Sig. & 8 \\
\hline
\end{tabular}


Total Variance Explained

\begin{tabular}{|c|c|c|c|c|c|c|}
\hline \multirow[b]{2}{*}{ Component } & \multicolumn{3}{|c|}{ Initial Eigenvalues } & \multicolumn{3}{|c|}{ Rotation Sums of Squared Loadings } \\
\hline & Total & $\%$ of Variance & Cumulative $\%$ & Total & $\%$ of Variance & Cumulative $\%$ \\
\hline 1 & 64.320 & 41.231 & 41.231 & 44.385 & 28.452 & 28.452 \\
\hline 2 & 36.594 & 23.458 & 64.688 & 31.872 & 20.431 & 48.883 \\
\hline 3 & 20.261 & 12.988 & 77.676 & 26.727 & 17.133 & 66.015 \\
\hline 4 & 7.634 & 4.894 & 82.569 & 14.244 & 9.131 & 75.146 \\
\hline 5 & 6.930 & 4.442 & 87.012 & 12.531 & 8.033 & 83.179 \\
\hline 6 & 4.675 & 2.997 & 90.008 & 7.209 & 4.621 & 87.800 \\
\hline 7 & 3.224 & 2.067 & 92.075 & 5.002 & 3.206 & 91.006 \\
\hline 8 & 2.650 & 1.698 & 93.774 & 2.635 & 1.689 & 92.695 \\
\hline 9 & 1.921 & 1.231 & 95.005 & 2.388 & 1.531 & 94.226 \\
\hline 10 & 1.493 & .957 & 95.961 & 2.312 & 1.482 & 95.708 \\
\hline 11 & 1.174 & .752 & 96.714 & 1.569 & 1.006 & 96.714 \\
\hline 12 & .801 & .513 & 97.227 & & & \\
\hline 13 & .711 & .456 & 97.683 & & & \\
\hline 14 & .610 & .391 & 98.074 & & & \\
\hline 15 & .543 & .348 & 98.422 & & & \\
\hline 16 & .489 & .313 & 98.735 & & & \\
\hline 17 & .302 & .193 & 98.928 & & & \\
\hline 18 & .280 & .180 & 99.108 & & & \\
\hline 19 & .200 & .128 & 99.236 & & & \\
\hline 20 & .172 & .110 & 99.346 & & & \\
\hline 21 & .159 & .102 & 99.448 & & & \\
\hline 22 & .147 & .094 & 99.542 & & & \\
\hline 23 & .109 & .070 & 99.612 & & & \\
\hline 24 & .086 & .055 & 99.667 & & & \\
\hline 25 & .082 & .053 & 99.720 & & & \\
\hline 26 & .071 & .046 & 99.766 & & & \\
\hline 27 & .060 & .039 & 99.804 & & & \\
\hline 28 & .053 & .034 & 99.838 & & & \\
\hline 29 & .045 & .029 & 99.867 & & & \\
\hline 30 & .035 & .023 & 99.889 & & & \\
\hline 31 & .030 & .019 & 99.908 & & & \\
\hline 32 & .027 & .017 & 99.926 & & & \\
\hline 33 & .024 & .016 & 99.941 & & & \\
\hline 34 & .020 & .013 & 99.954 & & & \\
\hline 35 & .019 & .012 & 99.966 & & & \\
\hline 36 & .016 & .010 & 99.977 & & & \\
\hline
\end{tabular}




\begin{tabular}{|c|c|c|c|}
\hline 37 & .011 & .007 & 99.983 \\
\hline 38 & .008 & .005 & 99.988 \\
\hline 39 & .005 & .003 & 99.992 \\
\hline 40 & .005 & .003 & 99.995 \\
\hline 41 & .004 & .002 & 99.997 \\
\hline 42 & .001 & .001 & 99.998 \\
\hline 43 & .001 & .001 & 99.999 \\
\hline 44 & .000 & .000 & 99.999 \\
\hline 45 & .000 & .000 & 99.999 \\
\hline 46 & .000 & .000 & 99.999 \\
\hline 47 & .000 & .000 & 100.000 \\
\hline 48 & .000 & $8.524 \mathrm{E}-5$ & 100.000 \\
\hline 49 & $6.488 \mathrm{E}-5$ & $4.159 \mathrm{E}-5$ & 100.000 \\
\hline 50 & $5.235 \mathrm{E}-5$ & $3.356 \mathrm{E}-5$ & 100.000 \\
\hline 51 & 4.245E-5 & $2.721 \mathrm{E}-5$ & 100.000 \\
\hline 52 & 3.947E-5 & $2.530 \mathrm{E}-5$ & 100.000 \\
\hline 53 & $3.446 \mathrm{E}-5$ & $2.209 \mathrm{E}-5$ & 100.000 \\
\hline 54 & $2.968 \mathrm{E}-5$ & $1.902 \mathrm{E}-5$ & 100.000 \\
\hline 55 & $2.659 \mathrm{E}-5$ & $1.705 \mathrm{E}-5$ & 100.000 \\
\hline 56 & $2.365 \mathrm{E}-5$ & $1.516 \mathrm{E}-5$ & 100.000 \\
\hline 57 & $2.282 \mathrm{E}-5$ & $1.463 \mathrm{E}-5$ & 100.000 \\
\hline 58 & $2.128 \mathrm{E}-5$ & $1.364 \mathrm{E}-5$ & 100.000 \\
\hline 59 & $1.921 \mathrm{E}-5$ & $1.231 \mathrm{E}-5$ & 100.000 \\
\hline 60 & $1.672 \mathrm{E}-5$ & $1.072 \mathrm{E}-5$ & 100.000 \\
\hline 61 & $1.546 \mathrm{E}-5$ & $9.908 \mathrm{E}-6$ & 100.000 \\
\hline 62 & $1.161 \mathrm{E}-5$ & 7.445E-6 & 100.000 \\
\hline 63 & $9.628 \mathrm{E}-6$ & $6.171 \mathrm{E}-6$ & 100.000 \\
\hline 64 & $9.357 \mathrm{E}-6$ & $5.998 \mathrm{E}-6$ & 100.000 \\
\hline 65 & 9.097E-6 & $5.832 \mathrm{E}-6$ & 100.000 \\
\hline 66 & $8.587 \mathrm{E}-6$ & $5.505 \mathrm{E}-6$ & 100.000 \\
\hline 67 & $7.805 \mathrm{E}-6$ & $5.003 \mathrm{E}-6$ & 100.000 \\
\hline 68 & $7.630 \mathrm{E}-6$ & $4.891 \mathrm{E}-6$ & 100.000 \\
\hline 69 & 7.127E-6 & $4.569 \mathrm{E}-6$ & 100.000 \\
\hline 70 & 7.005E-6 & $4.490 \mathrm{E}-6$ & 100.000 \\
\hline 71 & $6.956 \mathrm{E}-6$ & $4.459 \mathrm{E}-6$ & 100.000 \\
\hline 72 & $6.532 \mathrm{E}-6$ & 4.187E-6 & 100.000 \\
\hline 73 & $6.188 \mathrm{E}-6$ & $3.966 \mathrm{E}-6$ & 100.000 \\
\hline 74 & $5.862 \mathrm{E}-6$ & $3.758 \mathrm{E}-6$ & 100.000 \\
\hline 75 & $5.489 \mathrm{E}-6$ & $3.519 \mathrm{E}-6$ & 100.000 \\
\hline 76 & $5.274 \mathrm{E}-6$ & 3.381E-6 & 100.000 \\
\hline 77 & $5.144 \mathrm{E}-6$ & $3.298 \mathrm{E}-6$ & 100.000 \\
\hline
\end{tabular}




\begin{tabular}{|c|c|c|c|}
\hline 78 & $4.984 \mathrm{E}-6$ & 3.195E-6 & 100.000 \\
\hline 79 & $4.618 \mathrm{E}-6$ & $2.960 \mathrm{E}-6$ & 100.000 \\
\hline 80 & 4.546E-6 & $2.914 \mathrm{E}-6$ & 100.000 \\
\hline 81 & 4.443E-6 & $2.848 \mathrm{E}-6$ & 100.000 \\
\hline 82 & 4.390E-6 & $2.814 \mathrm{E}-6$ & 100.000 \\
\hline 83 & $4.120 \mathrm{E}-6$ & $2.641 \mathrm{E}-6$ & 100.000 \\
\hline 84 & $3.765 \mathrm{E}-6$ & $2.414 \mathrm{E}-6$ & 100.000 \\
\hline 85 & $3.571 \mathrm{E}-6$ & $2.289 \mathrm{E}-6$ & 100.000 \\
\hline 86 & 3.177E-6 & 2.037E-6 & 100.000 \\
\hline 87 & 3.163E-6 & $2.027 \mathrm{E}-6$ & 100.000 \\
\hline 88 & $2.986 \mathrm{E}-6$ & $1.914 \mathrm{E}-6$ & 100.000 \\
\hline 89 & $2.747 \mathrm{E}-6$ & $1.761 \mathrm{E}-6$ & 100.000 \\
\hline 90 & $2.549 \mathrm{E}-6$ & $1.634 \mathrm{E}-6$ & 100.000 \\
\hline 91 & $2.442 \mathrm{E}-6$ & $1.565 \mathrm{E}-6$ & 100.000 \\
\hline 92 & $2.206 \mathrm{E}-6$ & $1.414 \mathrm{E}-6$ & 100.000 \\
\hline 93 & 2.093E-6 & $1.341 \mathrm{E}-6$ & 100.000 \\
\hline 94 & $1.970 \mathrm{E}-6$ & $1.263 \mathrm{E}-6$ & 100.000 \\
\hline 95 & $1.804 \mathrm{E}-6$ & $1.156 \mathrm{E}-6$ & 100.000 \\
\hline 96 & $1.569 \mathrm{E}-6$ & $1.005 \mathrm{E}-6$ & 100.000 \\
\hline 97 & $1.458 \mathrm{E}-6$ & $9.344 \mathrm{E}-7$ & 100.000 \\
\hline 98 & $1.354 \mathrm{E}-6$ & 8.677E-7 & 100.000 \\
\hline 99 & $1.240 \mathrm{E}-6$ & 7.951E-7 & 100.000 \\
\hline 100 & $1.135 \mathrm{E}-6$ & $7.278 \mathrm{E}-7$ & 100.000 \\
\hline 101 & $1.087 \mathrm{E}-6$ & $6.970 \mathrm{E}-7$ & 100.000 \\
\hline 102 & $1.019 \mathrm{E}-6$ & $6.532 \mathrm{E}-7$ & 100.000 \\
\hline 103 & $9.446 \mathrm{E}-7$ & $6.055 \mathrm{E}-7$ & 100.000 \\
\hline 104 & $9.349 \mathrm{E}-7$ & $5.993 \mathrm{E}-7$ & 100.000 \\
\hline 105 & $9.029 \mathrm{E}-7$ & $5.788 \mathrm{E}-7$ & 100.000 \\
\hline 106 & $8.626 \mathrm{E}-7$ & $5.529 \mathrm{E}-7$ & 100.000 \\
\hline 107 & $8.232 \mathrm{E}-7$ & $5.277 \mathrm{E}-7$ & 100.000 \\
\hline 108 & 8.017E-7 & $5.139 \mathrm{E}-7$ & 100.000 \\
\hline 109 & 7.742E-7 & 4.963E-7 & 100.000 \\
\hline 110 & 7.491E-7 & $4.802 \mathrm{E}-7$ & 100.000 \\
\hline 111 & $7.258 \mathrm{E}-7$ & 4.653E-7 & 100.000 \\
\hline 112 & 7.037E-7 & $4.511 \mathrm{E}-7$ & 100.000 \\
\hline 113 & $6.969 \mathrm{E}-7$ & 4.467E-7 & 100.000 \\
\hline 114 & 6.695E-7 & $4.291 \mathrm{E}-7$ & 100.000 \\
\hline 115 & $6.644 \mathrm{E}-7$ & $4.259 \mathrm{E}-7$ & 100.000 \\
\hline 116 & $6.434 \mathrm{E}-7$ & $4.124 \mathrm{E}-7$ & 100.000 \\
\hline 117 & $6.374 \mathrm{E}-7$ & $4.086 \mathrm{E}-7$ & 100.000 \\
\hline 118 & $6.181 \mathrm{E}-7$ & 3.962E-7 & 100.000 \\
\hline
\end{tabular}




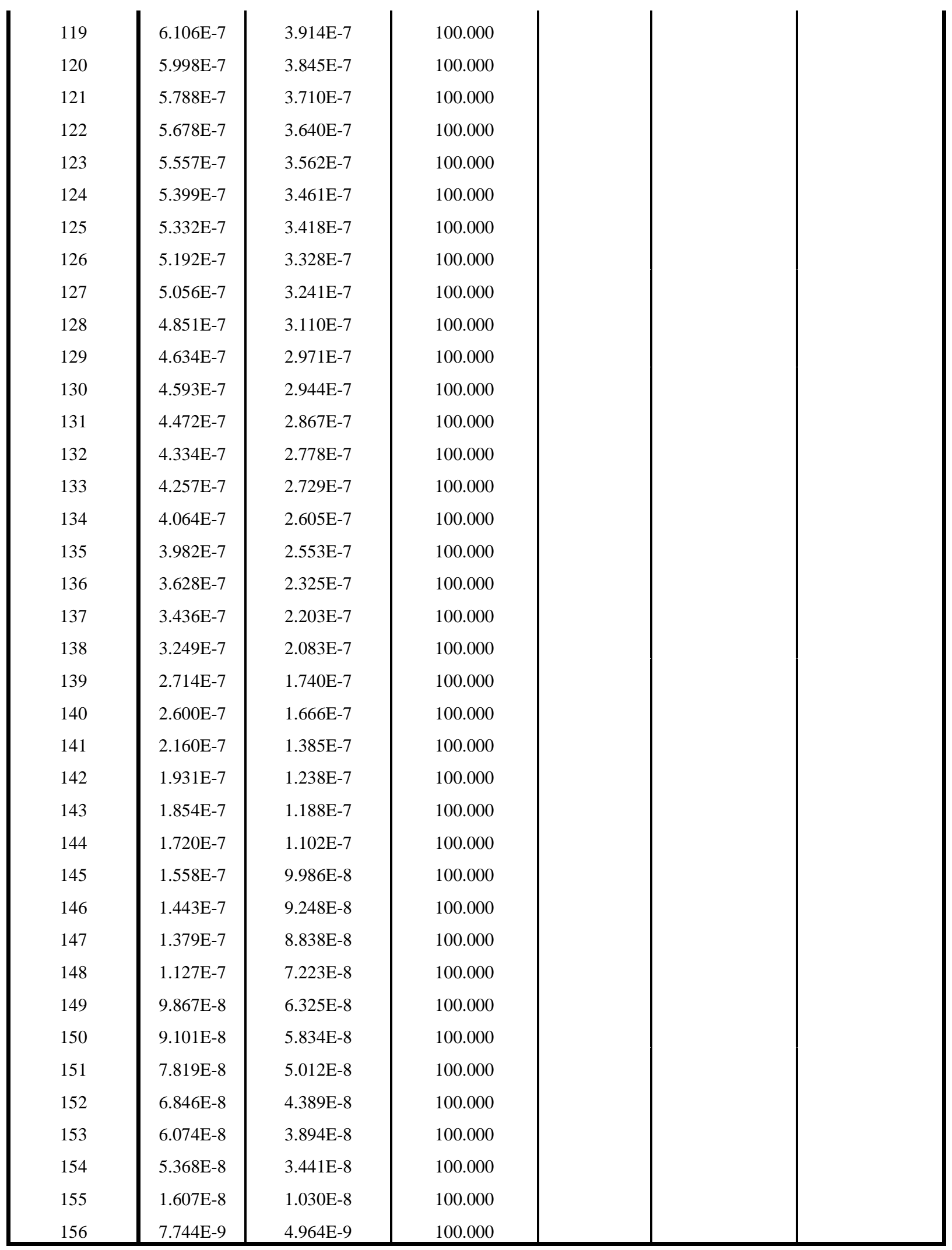


Rotated Component Matrix ${ }^{\mathrm{a}}$

\begin{tabular}{|c|c|c|c|c|c|c|c|c|c|c|c|}
\hline & \multicolumn{11}{|c|}{ Component } \\
\hline & 1 & 2 & 3 & 4 & 5 & 6 & 7 & 8 & 9 & 10 & 11 \\
\hline AMinTJAN & .947 & .121 & -.205 & -.044 & -.170 & -.079 & .049 & -.059 & .014 & .002 & .001 \\
\hline AMinTFEB & .947 & .066 & -.198 & -.070 & -.193 & -.055 & .043 & -.081 & .036 & .012 & -.010 \\
\hline AMinTMAR & .960 & -.038 & -.187 & -.034 & -.154 & .009 & .071 & -.082 & .045 & .016 & .004 \\
\hline AMinTOCT & .977 & .028 & -.110 & -.040 & -.019 & .090 & .043 & -.041 & .023 & .109 & .026 \\
\hline AMinTNOV & .980 & .087 & -.080 & -.017 & -.079 & .032 & .053 & -.049 & .040 & .078 & .019 \\
\hline AMinTDEC & .965 & .136 & -.129 & -.032 & -.140 & -.037 & .051 & -.037 & .029 & .038 & .018 \\
\hline AMinTANNUAL & .977 & -.008 & -.164 & -.006 & -.067 & .024 & .066 & -.046 & .011 & .070 & .017 \\
\hline DWMinTE00JAN & -.964 & -.050 & .135 & .019 & .123 & .061 & -.075 & .093 & .007 & -.061 & .044 \\
\hline DWMinTE00FEB & -.936 & .052 & .260 & -.035 & -.045 & .057 & -.080 & .107 & .018 & -.078 & .057 \\
\hline DWMinTE00DEC & -.959 & .014 & .157 & -.043 & -.076 & .003 & -.066 & .078 & .033 & -.125 & .017 \\
\hline DWMinTE00ANNUAL & -.944 & .024 & .242 & -.044 & -.078 & .038 & -.064 & .050 & .037 & -.097 & .027 \\
\hline AMaxTMAR & .896 & -.021 & -.292 & -.050 & -.249 & -.111 & .080 & -.010 & .056 & -.115 & -.048 \\
\hline AMaxTAPR & .929 & .003 & -.270 & .025 & -.158 & -.108 & .090 & .005 & .021 & -.108 & -.010 \\
\hline AMaxTMAY & .928 & .029 & -.253 & .039 & -.160 & -.143 & .078 & .016 & .009 & -.117 & -.012 \\
\hline AMaxTJUNE & .927 & -.084 & -.268 & .108 & -.072 & -.091 & .088 & .073 & -.006 & -.108 & -.008 \\
\hline AMaxTJULY & .908 & -.189 & -.259 & .137 & .002 & -.030 & .064 & .152 & .004 & -.079 & -.005 \\
\hline AMaxTAUG & .921 & -.137 & -.224 & .156 & .023 & -.003 & .061 & .175 & -.006 & -.086 & .013 \\
\hline AMaxTSEP & .937 & -.046 & -.215 & .119 & -.055 & -.086 & .080 & .126 & .014 & -.116 & .004 \\
\hline AMaxTOCT & .936 & .063 & -.199 & .021 & -.167 & -.133 & .076 & .057 & .029 & -.120 & -.018 \\
\hline AMaxTANNUAL & .922 & .023 & -.251 & .029 & -.180 & -.138 & .079 & .036 & .018 & -.133 & -.019 \\
\hline AMDTJAN & .903 & .126 & -.238 & -.045 & -.250 & -.153 & .064 & -.046 & .014 & -.092 & -.019 \\
\hline AMDTFEB & .915 & .066 & -.250 & -.075 & -.239 & -.122 & .050 & -.047 & .034 & -.073 & -.030 \\
\hline AMDTMAR & .938 & -.028 & -.239 & -.042 & -.201 & -.049 & .078 & -.047 & .051 & -.046 & -.021 \\
\hline
\end{tabular}




\begin{tabular}{|l|l} 
AMDTAPR & .958 \\
AMDTMAY & .963 \\
AMDTJUNE & .958 \\
AMDTJULY & .945 \\
AMDTAUG & .961 \\
AMDTSEP & .979 \\
AMDTOCT & .980 \\
AMDTNOV & .960 \\
AMDTDEC & .915 \\
AMDTANNUAL & .966 \\
ARHPMAR & -.303 \\
ARHPAPR & -.133 \\
ARHPMAY & -.532 \\
ARHPJUNE & -.145 \\
ARHPSEP & .089 \\
ARHPOCT & -.374 \\
ARHPANNUAL & -.271 \\
AMaxRHPMAR & -.390 \\
AMaxRHPAPR & -.651 \\
AMaxRHPMAY & -.604 \\
AMaxRHPJUNE & -.186 \\
AMaxRHPSEP & .024 \\
AMaxRHPOCT & -.368 \\
AMaxRHPANNUAL & -.320 \\
AMinRHPMAR & -.198 \\
AMinRHPAPR & -.583 \\
AMinRHPMAY & -.441 \\
&
\end{tabular}

\begin{tabular}{|c|c|c|c|}
\hline-.044 & -.225 & $\mid .014$ & |-.124 \\
\hline-.032 & -.209 & .028 & -.113 \\
\hline-.103 & -.236 & .066 & -.039 \\
\hline-.163 & -.226 & .093 & .023 \\
\hline-.092 & -.183 & .093 & .039 \\
\hline .003 & -.174 & .051 & -.010 \\
\hline .046 & -.153 & -.011 & -.088 \\
\hline .122 & -.138 & -.003 & -.163 \\
\hline .179 & -.170 & -.036 & -.242 \\
\hline .007 & -.208 & .011 & -.117 \\
\hline .717 & .438 & .350 & .053 \\
\hline .570 & .349 & .060 & .443 \\
\hline .583 & .403 & .229 & .056 \\
\hline .913 & .299 & .064 & -.053 \\
\hline .947 & .206 & .138 & -.042 \\
\hline .755 & .311 & .280 & .131 \\
\hline .800 & .365 & .261 & .133 \\
\hline .728 & .320 & .289 & .004 \\
\hline .580 & .318 & .188 & .009 \\
\hline .578 & .362 & .227 & .059 \\
\hline .879 & .351 & .150 & -.066 \\
\hline .930 & .234 & .136 & -.057 \\
\hline .794 & .317 & .219 & .033 \\
\hline .812 & .318 & .205 & .055 \\
\hline .635 & .541 & .276 & .156 \\
\hline .385 & .428 & .134 & .012 \\
\hline .548 & .373 & .140 & .085 \\
\hline
\end{tabular}

\begin{tabular}{|l|l}
-.044 & .089 \\
-.057 & .087 \\
-.013 & .088 \\
.015 & .070 \\
.052 & .065 \\
.002 & .062 \\
-.015 & .059 \\
-.080 & .071 \\
-.151 & .059 \\
-.055 & .071 \\
-.003 & .070 \\
.267 & .167 \\
.286 & .085 \\
.082 & .013 \\
-.035 & -.004 \\
.170 & .027 \\
.070 & .046 \\
-.159 & .055 \\
-.005 & .018 \\
.160 & .043 \\
.008 & .025 \\
-.107 & -.006 \\
-.027 & .013 \\
-.069 & .037 \\
.197 & .035 \\
.313 & .037 \\
.378 & .060 \\
\end{tabular}

\begin{tabular}{|l|l}
-.032 & .027 \\
-.031 & .016 \\
.008 & -.011 \\
.079 & -.012 \\
.084 & -.024 \\
.042 & -.006 \\
.001 & .025 \\
-.041 & .028 \\
-.034 & .021 \\
-.007 & .014 \\
.135 & -.158 \\
.214 & .165 \\
.190 & -.037 \\
.051 & -.007 \\
.081 & -.051 \\
.198 & -.043 \\
.195 & -.070 \\
.231 & -.126 \\
.252 & -.046 \\
.253 & .002 \\
.093 & .068 \\
.146 & .012 \\
.252 & .029 \\
.264 & -.010 \\
.070 & -.191 \\
-.008 & -.123 \\
.086 & -.105 \\
\end{tabular}

\begin{tabular}{|l|l}
-.032 & .005 \\
-.024 & .004 \\
-.007 & .009 \\
.030 & .010 \\
.051 & .027 \\
.021 & .017 \\
.005 & .004 \\
-.034 & .003 \\
-.086 & -.006 \\
-.023 & .001 \\
.007 & .048 \\
.307 & -.006 \\
.152 & -.030 \\
.151 & -.044 \\
.064 & -.009 \\
.118 & .016 \\
.094 & -.006 \\
-.086 & -.001 \\
-.002 & -.080 \\
.045 & -.062 \\
.073 & -.051 \\
-.007 & -.040 \\
-.009 & -.038 \\
-.018 & -.050 \\
.232 & .009 \\
.379 & -.124 \\
.386 & -.074 \\
\end{tabular}




\begin{tabular}{|c|c|}
\hline AMinRHPJUNE & | -.096 \\
\hline AMinRHPSEP & .080 \\
\hline AMinRHPOCT & -.422 \\
\hline MTPJAN & -.138 \\
\hline MTPFEB & -.164 \\
\hline MTPMAR & -.324 \\
\hline MTPAPR & -.479 \\
\hline MTPMAY & -.395 \\
\hline MTPJUNE & .298 \\
\hline MTPJULY & -.048 \\
\hline MTPAUG & .245 \\
\hline MTPSEP & .141 \\
\hline МТРОСТ & -.300 \\
\hline MTPNOV & -.364 \\
\hline MTPDEC & -.330 \\
\hline MTPJAN_10 & -.106 \\
\hline MTPFEB_10 & -.201 \\
\hline MTPMAR_10 & -.357 \\
\hline MTPAPR_10 & -.396 \\
\hline MTPMAY_10 & -.306 \\
\hline MTPJUNE_10 & .278 \\
\hline MTPJULY_10 & .398 \\
\hline MTPAUG_10 & .309 \\
\hline MTPSEP_10 & .265 \\
\hline MTPOCT_10 & -.163 \\
\hline MTPNOV_10 & -.350 \\
\hline MTPDEC_10 & -.359 \\
\hline
\end{tabular}

\begin{tabular}{|l|l}
.889 & .186 \\
.921 & .121 \\
.563 & .232 \\
.562 & .770 \\
.431 & .858 \\
.354 & .853 \\
.035 & .851 \\
.054 & .611 \\
.738 & .166 \\
.833 & .071 \\
.869 & .113 \\
.753 & .428 \\
.229 & .896 \\
.084 & .903 \\
.376 & .843 \\
.660 & .685 \\
.423 & .846 \\
.458 & .787 \\
.023 & .893 \\
.045 & .651 \\
.669 & .155 \\
.683 & .118 \\
.853 & .060 \\
.682 & .095 \\
.173 & .931 \\
.142 & .882 \\
.427 & .800 \\
\end{tabular}

\begin{tabular}{|l|l}
-.064 & -.069 \\
.108 & .006 \\
.246 & .253 \\
-.046 & -.033 \\
.099 & -.067 \\
.074 & -.038 \\
.124 & .089 \\
.127 & .423 \\
-.198 & .000 \\
-.159 & -.223 \\
-.193 & -.125 \\
-.014 & .025 \\
.098 & .046 \\
.055 & .030 \\
-.012 & -.020 \\
-.056 & -.038 \\
.114 & -.052 \\
.086 & -.065 \\
.128 & .067 \\
.091 & .355 \\
-.203 & -.016 \\
-.313 & -.153 \\
-.222 & -.058 \\
.049 & -.045 \\
.055 & .001 \\
.094 & .021 \\
-.016 & -.064 \\
\end{tabular}

\begin{tabular}{|l|l}
.202 & -.018 \\
.068 & .007 \\
.336 & -.003 \\
-.144 & -.151 \\
-.065 & -.098 \\
.007 & -.093 \\
.097 & -.006 \\
.423 & -.019 \\
-.136 & .032 \\
-.064 & -.129 \\
-.161 & -.126 \\
.104 & .004 \\
.117 & -.031 \\
.094 & -.035 \\
-.079 & -.117 \\
-.156 & -.162 \\
-.074 & -.085 \\
-.009 & -.089 \\
.061 & .005 \\
.423 & .030 \\
-.168 & .062 \\
-.094 & .172 \\
-.115 & -.120 \\
.079 & .059 \\
.076 & -.027 \\
.109 & -.049 \\
-.055 & -.136 \\
\end{tabular}

\begin{tabular}{|l|l}
-.026 & -.122 \\
.021 & -.160 \\
.116 & -.137 \\
-.037 & -.080 \\
-.100 & -.075 \\
-.122 & -.051 \\
-.010 & .031 \\
.033 & .085 \\
.034 & .444 \\
-.379 & -.003 \\
-.166 & -.058 \\
.041 & .331 \\
.052 & .034 \\
.101 & .063 \\
.009 & -.058 \\
-.039 & -.100 \\
-.139 & -.066 \\
-.100 & -.027 \\
.049 & .040 \\
.135 & .076 \\
.094 & .543 \\
-.048 & .231 \\
-.151 & -.076 \\
.004 & .513 \\
.041 & -.044 \\
.132 & .144 \\
.045 & -.056 \\
\end{tabular}

\begin{tabular}{|l|l}
.276 & -.068 \\
.242 & -.038 \\
.372 & -.022 \\
-.051 & -.018 \\
-.012 & .016 \\
-.003 & .008 \\
.063 & -.020 \\
.048 & .188 \\
-.078 & .076 \\
-.067 & .156 \\
-.050 & .126 \\
-.111 & .077 \\
.021 & -.067 \\
.030 & -.061 \\
-.020 & -.041 \\
-.046 & .023 \\
-.017 & .044 \\
.001 & .069 \\
.068 & -.035 \\
.027 & .158 \\
-.047 & .043 \\
-.113 & .129 \\
-.051 & .103 \\
-.111 & -.149 \\
-.023 & -.106 \\
-.030 & -.004 \\
-.032 & -.003 \\
\end{tabular}




\begin{tabular}{|l|l} 
MTPANNUAL_10 & -.170 \\
DWPJAN & -.570 \\
DWPFEB & -.421 \\
DWPMAR & -.528 \\
DWPAPR & -.677 \\
DWPMAY & -.379 \\
DWPJUNE & -.184 \\
DWPJULY & -.193 \\
DWPAUG & -.146 \\
DWPSEP & -.155 \\
DWPOCT & -.473 \\
DWPNOV & -.580 \\
DWPDEC & -.586 \\
DWPANNUAL & -.574 \\
DWTSMAR & .259 \\
DWTSAPR & -.206 \\
DWTSMAY & -.173 \\
DWTSJUNE & .223 \\
DWTSOCT & .051 \\
DWTSANNUAL & .156 \\
DWDAPR & .344 \\
DWDMAY & .276 \\
DWDJUNE & .529 \\
DWDJULY & .601 \\
DWDAUG & .086 \\
DWDSEP & \\
DWDANNUAL & \\
&
\end{tabular}

\begin{tabular}{|c|c|c|c|c|c|c|c|}
\hline .299 & .218 & .260 & .454 & .542 & $\mid .031$ & .278 & $\mid .270$ \\
\hline .110 & .485 & .175 & .544 & .097 & -.041 & -.077 & .019 \\
\hline .176 & .568 & .332 & .348 & .176 & .082 & -.240 & .012 \\
\hline .122 & .538 & .431 & .387 & .035 & .073 & -.110 & -.063 \\
\hline-.161 & .371 & .174 & .461 & .243 & .111 & .017 & .092 \\
\hline-.200 & .318 & .151 & .611 & .453 & .105 & .076 & .150 \\
\hline .774 & .300 & -.200 & .243 & .188 & -.049 & .080 & .296 \\
\hline .178 & .236 & .416 & .535 & -.025 & .263 & .117 & .000 \\
\hline .872 & .155 & -.135 & -.070 & -.071 & -.199 & -.272 & -.016 \\
\hline .401 & .554 & .334 & .283 & .231 & .087 & .129 & .145 \\
\hline .213 & .599 & .206 & .226 & .404 & .048 & .179 & .180 \\
\hline .052 & .522 & .199 & .398 & .255 & .049 & .249 & .160 \\
\hline .027 & .468 & .156 & .561 & .075 & -.052 & .070 & .064 \\
\hline .147 & .522 & .218 & .471 & .215 & .033 & -.014 & .092 \\
\hline .351 & .578 & .374 & .248 & -.287 & .243 & $\mid-.169$ & -.108 \\
\hline-.283 & .447 & .381 & .581 & -.079 & .269 & -.097 & .063 \\
\hline-.042 & .275 & .349 & .671 & .232 & .259 & .018 & .257 \\
\hline .785 & .233 & -.005 & .220 & .000 & .088 & .083 & .437 \\
\hline .693 & .569 & .127 & -.075 & .077 & .127 & .105 & .239 \\
\hline .548 & .628 & .220 & .297 & -.108 & .206 & -.039 & .240 \\
\hline-.265 & -.304 & .003 & .339 & -.003 & .731 & .023 & .006 \\
\hline-.380 & -.233 & .104 & .229 & .007 & .777 & .024 & .014 \\
\hline-.156 & -.124 & .162 & .138 & -.017 & .773 & -.017 & .056 \\
\hline-.016 & -.098 & .062 & -.092 & .066 & .764 & .000 & .015 \\
\hline-.019 & .028 & -.103 & -.704 & -.075 & -.060 & -.548 & -.179 \\
\hline .018 & -.094 & .065 & .082 & .093 & .774 & .073 & .020 \\
\hline-.227 & -.216 & .022 & .063 & .028 & .811 & .023 & .017 \\
\hline
\end{tabular}

\begin{tabular}{|l|l}
.129 & .179 \\
.143 & .011 \\
.271 & .098 \\
.055 & .163 \\
.199 & -.017 \\
.207 & .092 \\
.121 & .143 \\
.388 & .236 \\
.010 & .158 \\
.250 & .276 \\
.157 & .072 \\
.131 & .047 \\
.171 & .026 \\
.180 & .089 \\
.095 & -.115 \\
.173 & -.151 \\
.247 & .050 \\
.032 & .052 \\
.056 & .049 \\
.086 & -.043 \\
-.120 & -.089 \\
.012 & -.038 \\
.054 & .053 \\
.061 & .075 \\
-.016 & .002 \\
.085 & .030 \\
-.039 \\
\end{tabular}




\begin{tabular}{|c|c|c|c|c|c|c|c|c|c|c|}
\hline AWSJAN & -.420 & -.052 & -.168 & -.755 & -.314 & -.141 & -.072 & -.168 & .022 & -.086 \\
\hline AWSFEB & -.408 & .034 & -.164 & -.807 & -.266 & -.104 & -.122 & -.117 & .019 & -.093 \\
\hline AWSMAR & -.407 & .055 & -.111 & -.848 & -.176 & -.063 & -.070 & .012 & .055 & -.127 \\
\hline AWSAPR & -.200 & .219 & -.037 & -.918 & -.066 & -.006 & -.045 & .109 & .048 & -.047 \\
\hline AWSMAY & -.067 & .104 & -.088 & -.966 & -.058 & .022 & .006 & .090 & .020 & .021 \\
\hline AWSJUNE & .286 & -.003 & -.153 & -.920 & .052 & -.036 & .031 & .040 & -.039 & .026 \\
\hline AWSJULY & .417 & .044 & -.167 & -.813 & -.131 & -.119 & -.061 & -.024 & -.093 & -.061 \\
\hline AWSAUG & .395 & .131 & -.146 & -.781 & -.219 & -.106 & -.109 & -.041 & -.133 & -.069 \\
\hline AWSSEP & .259 & .229 & -.077 & -.903 & -.094 & -.084 & -.024 & -.020 & -.065 & .017 \\
\hline AWSOCT & -.062 & .009 & -.071 & -.960 & -.054 & .057 & .073 & -.036 & .026 & .114 \\
\hline AWSNOV & -.234 & -.080 & -.081 & -.910 & -.141 & -.015 & -.013 & -.067 & .080 & .080 \\
\hline AWSDEC & -.374 & -.164 & -.139 & -.776 & -.266 & -.133 & -.037 & -.153 & .061 & -.075 \\
\hline AWSANNUAL & -.079 & .062 & -.134 & -.964 & -.163 & -.070 & -.048 & -.035 & -.005 & -.041 \\
\hline PCDJAN & -.105 & -.664 & -.197 & .323 & .313 & .151 & .172 & -.060 & .095 & -.014 \\
\hline PCDFEB & .098 & -.754 & -.121 & .134 & -.041 & .467 & .083 & -.155 & .105 & .166 \\
\hline PCDMAR & -.053 & -.724 & -.153 & .368 & -.005 & .363 & .255 & -.100 & -.101 & -.019 \\
\hline PCDAPR & -.332 & -.770 & -.104 & .273 & .097 & .302 & .124 & -.146 & -.057 & .104 \\
\hline PCDMAY & .037 & .229 & .284 & -.074 & -.726 & -.177 & -.014 & .018 & .123 & -.183 \\
\hline PCDNOV & -.526 & -.603 & .006 & .236 & .381 & .123 & -.035 & .082 & -.042 & .030 \\
\hline PCDDEC & -.265 & -.792 & -.052 & .286 & .266 & .148 & .053 & -.019 & -.025 & .112 \\
\hline PCDANNUAL & -.530 & -.535 & -.066 & .120 & .177 & .405 & .015 & -.224 & -.043 & .060 \\
\hline CDJAN & -.230 & -.132 & -.031 & .169 & .894 & .148 & -.020 & -.125 & -.119 & -.173 \\
\hline CDFEB & -.525 & -.125 & .028 & .298 & .652 & -.014 & -.022 & -.231 & -.146 & -.199 \\
\hline CDMAR & -.381 & -.252 & .066 & .274 & .791 & .027 & .098 & -.033 & -.060 & -.156 \\
\hline CDAPR & -.525 & -.404 & .031 & .060 & .680 & .131 & .101 & .135 & .084 & -.065 \\
\hline CDDEC & -.409 & -.290 & -.026 & .177 & .771 & .285 & .059 & .042 & -.061 & -.072 \\
\hline CDANNUAL & -.472 & -.259 & .061 & .160 & .778 & .204 & .056 & .066 & .017 & -.102 \\
\hline
\end{tabular}




\begin{tabular}{|c|c|c|c|c|c|c|c|c|c|c|c|}
\hline MTSHMAR & | -.091 & .255 & -.104 & -.397 & $\mid-.443$ & -.621 & -.145 & .116 & $\mid .249$ & .144 & | -.099 \\
\hline MTSHAPR & .372 & .530 & -.098 & -.077 & -.249 & -.685 & -.014 & -.066 & .033 & .018 & .056 \\
\hline MTSHMAY & .052 & .280 & .060 & .038 & -.108 & -.923 & -.030 & .068 & -.055 & .022 & .080 \\
\hline MTSHJUN & -.105 & -.615 & .042 & .168 & .521 & -.266 & .112 & .417 & .006 & .043 & .158 \\
\hline MTSHJUL & .060 & -.833 & -.088 & .236 & .400 & -.059 & .184 & .076 & .040 & .060 & .075 \\
\hline MTSHAUG & -.104 & -.834 & -.207 & .208 & .375 & -.146 & .092 & .069 & -.007 & .071 & .076 \\
\hline MTSHSEP & -.166 & -.807 & -.079 & .094 & .130 & -.434 & .121 & .120 & .158 & -.030 & .009 \\
\hline MTSHOCT & .345 & -.076 & -.232 & -.133 & -.393 & -.768 & -.011 & -.141 & -.039 & -.073 & -.060 \\
\hline MTSHANNUAL & .246 & -.188 & -.223 & -.135 & -.259 & -.842 & .061 & .024 & .107 & .008 & .041 \\
\hline PRWINTER & -.218 & .450 & .841 & .045 & -.046 & -.064 & -.114 & -.090 & -.068 & -.021 & .002 \\
\hline PRSPRING & -.413 & .175 & .836 & .092 & .178 & .160 & -.004 & .007 & .127 & .046 & .048 \\
\hline PRSUMMER & .150 & .894 & .159 & -.165 & -.140 & -.097 & -.113 & -.210 & .020 & -.069 & .135 \\
\hline PRAUTUMN & -.348 & .257 & .890 & .024 & .005 & .005 & -.080 & .049 & -.004 & .003 & -.052 \\
\hline DWPWINTER_10 & -.231 & .529 & .789 & .048 & -.054 & -.080 & -.115 & -.093 & -.065 & -.021 & .047 \\
\hline DWPSPRING_10 & -.344 & .126 & .880 & .093 & .140 & .131 & .021 & .086 & .128 & .053 & .020 \\
\hline DWPSUMMER_10 & -.044 & .027 & .116 & .335 & .410 & -.140 & .382 & -.075 & -.225 & .358 & .058 \\
\hline DWPAUTUMN_10 & -.346 & .310 & .870 & .031 & -.028 & .017 & -.097 & .077 & .016 & -.032 & -.015 \\
\hline DWPWINTER_5 & -.291 & .513 & .760 & .110 & .023 & -.031 & -.141 & -.128 & -.089 & -.016 & .089 \\
\hline DWPSPRING_5 & -.516 & .197 & .736 & .121 & .196 & .200 & .014 & -.063 & .151 & .067 & .074 \\
\hline DWPSUMMER_5 & .145 & .869 & .150 & -.159 & -.154 & -.027 & -.079 & -.279 & .096 & -.096 & .136 \\
\hline DWPAUTUMN_5 & -.467 & .267 & .819 & .051 & .079 & .047 & -.094 & .086 & .023 & .003 & -.034 \\
\hline DWPWINTER & -.523 & .141 & .550 & .327 & .438 & .106 & .041 & -.149 & -.012 & .162 & .096 \\
\hline DWPSPRING & -.562 & -.064 & .382 & .132 & .546 & .351 & .099 & .053 & .156 & .215 & .049 \\
\hline DWPSUMMER & -.196 & .845 & .246 & -.077 & -.006 & -.026 & -.144 & -.271 & .076 & .029 & .224 \\
\hline DWPAUTUMN & -.580 & .082 & .538 & .191 & .441 & .224 & .008 & .167 & .130 & .159 & .046 \\
\hline
\end{tabular}

Extraction Method: Principal Component Analysis. 